\title{
Electricity Market Design for Generator Revenue Sufficiency with Increased Variable Generation
}

\author{
Todd Levin $^{1 *}$ and Audun Botterud ${ }^{1}$
}

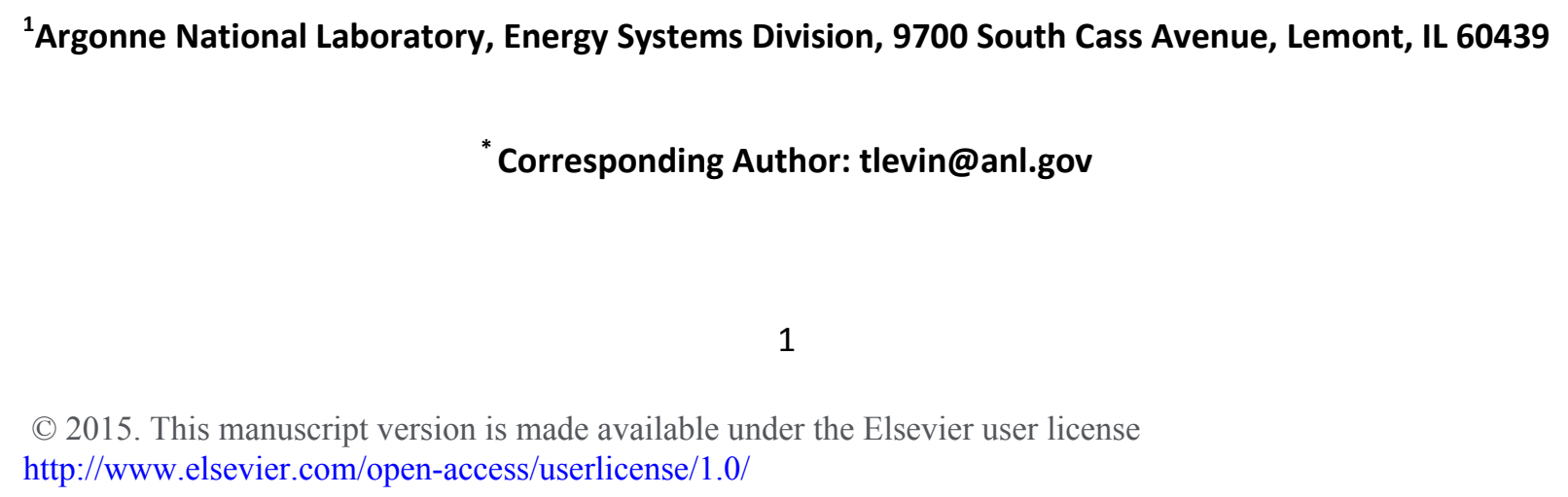




\section{Abstract}

We present a computationally efficient mixed-integer program (MIP) that determines optimal generator expansion decisions, and hourlyunit commitment and dispatch in a power system. The impact of increasing wind power capacity on the optimal generation mix and generator profitability is analyzed for a test case that approximates the electricity market in Texas(ERCOT). We analyze three market policies that may support resource adequacy: Operating Reserve Demand Curves (ORDC), Fixed Reserve Scarcity Prices (FRSP) and fixed capacity payments (CP). Optimal expansion plans are comparable between the ORDC and FRSP implementations, while capacity payments may result in additional new capacity. The FRSP policy leads to frequent reserves scarcity events and corresponding price spikes, while the ORDC implementation results in more continuous energy prices. Average energy prices decrease with increasing wind penetration under all policies, as do revenues for baseload and wind generators. Intermediate and peak load plants benefit from higher reserve prices and are less exposed to reduced energy prices. All else equal, an ORDC approach may be preferred to FRSP as it results in similar expansion and revenues with less extreme energy prices. A fixed CPleads to additional new flexible NGCT units, but lower profits for other technologies.

Keywords: Resource Adequacy, Revenue Sufficiency, Variable Energy Resource, ORDC, Scarcity Pricing, ERCOT

\section{Introduction}

In an economically efficient market, prices are set to the level that consumers are willing to pay for an additional unit of consumption. When supply is not constrained, this market clearing price tends towards the supplier's marginal cost of production. If supply becomes scarce, prices increase until consumers voluntarily reduce their consumption. Suppliers rely on these "scarcity rents", i.e. the 
difference between the scarcity price and the highest marginal production cost, in order to recover their fixed operational costs.

Electricity markets have unique properties that cause them to deviate somewhat from theoretical freemarket principles. Primary among these is the fact that the prices paid by electricity consumers are largely disaggregated from the real-time cost of service provision. Consumers therefore do not receive the price signals that would normally cause them to reduce their consumption during periods where demand exceeds supply. At the same time, the ability to reduce consumption in real-time is limited for most electricity consumers. This can result in situations where the available supply is unable to meet demand at any price, potentially leading to curtailments and essentially unbounded real-time costs of service provision when markets do not clear (Cramton et al., 2013).

One solution to thisform of market failure is the implementation of an administratively determined price cap to help alleviate market power and price gouging concerns during periods of resource scarcity. However, generation resources also rely on these periods of scarcity to cover their fixed costs of construction and operation.Particularly, those generation resources with the greatest marginal costs could never recover their fixed costs without such periods of scarcity pricing. Price caps limit the revenue available to generators during these periods, resulting in the so-called "missing money problem"(Shanker, 2003; Hogan, 2005). As a result, generators are not properly incentivized to contribute to system reliability by providing generation during periods of extreme scarcity. Generators may also be discouraged from entering the market at all, due to concerns over their ability to recover fixed costs when electricity prices are capped. This in turn leads to the "resource adequacy problem", where over the long term, insufficient capacity may be developed to serve demand and ensure system reliability. 
These issues are further compounded by the growing presence of variable energy resources (VERs) in modern electric systems, which present two primary new challenges to system operation.

1) VERs have zero or near-zero marginal costs of generation, which depress overall prices when VERs provide the marginal unit of generation in a system. They may in fact even have a negative marginal cost of generation when considering tax incentives, such as the Production Tax Credit (PTC) in the United States. In the presence of these incentives, generators are actually willing to pay a small amount to generate electricity so they are able to claim the tax credits for each unit of generation. This reduction in wholesale prices, and therefore generator revenues, may intensify the resource adequacy problem.

2) As VERs have highly variable generation output profiles with limited predictability, a system with high VER penetration must maintain additional operating reserves in order to ensure system reliability. Such services may not always be appropriately compensated under many existing market design mechanisms. In the United States an Independent System Operator (ISO) or Regional Transmission Operator (RTO) (hereafter jointly referred to as a RTO) is an independent entity tasked with procuring generation and reserves to serve demand and ensure system reliability throughout their footprint. These resources are procured through market-based mechanisms where suppliers bid generation and reserves capacity into a market. The goal of this procedure is to produce a system-optimal outcome that is coordinated by the RTO as a centralized, regulated entity. This contrasts to some degree with a traditional competitive market in other sectors where a market equilibrium would be achieved through interactions between numerous independent buyers and sellers. To obtain the optimal system schedule, the offers for energy and reserves are usually co-optimized by the RTO to minimize the cost of provision across the system. The solution corresponds to a fully competitive market as long as market participants offer their true costs to the RTO. As a result of the co-optimization, the system prices for load and reserves are 
interdependent. The RTO must therefore implement a mechanism for valuing incremental reserves capacity.

Currently, two primary approaches for the pricing of reserves products are commonly implemented.

1) During each period of operation, the RTO sets target levels for various reserves products (e.g. spinning reserves, non-spinning reserves, and regulation). In the event that these levels are not achieved, a penalty cost is assessed. We will refer to this approach as a Fixed Reserve Scarcity Price (FRSP). When a reserve level falls short of the target, the price of providing that product is set at the administratively determined scarcity cost.

2) The RTO values reserve capacity based on a continuous function that decreases with increasing reserves. Therefore, as the reserves level increases, the market price for the reserves product decreases. This approach, proposed by Hogan (2005), will be referred to as an Operating Reserves Demand Curve (ORDC). The ORDC approach was recently implemented in the ERCOT system in Texas.

RTOs may also operate hybrid systems which have two or more discrete penalty levels that increase with the severity of the scarcity event.

Capacity payments (CP) are a third mechanism that may also be employed as a means of ensuring longterm resource adequacy.Under this mechanism revenue is provided to generators for having available capacity, regardless of their provision of electricity, reserves or other ancillary services. Such an approach can be implemented in one of two primary ways.

1) A regulating body establishes a target capacity level that would provide an appropriate level of system reliability for a given planning period. A capacity market is then established where generators can bid in existing and potential new capacity, and the market clearing price for capacity is determined. 
2) Alternatively, a fixed capacity payment may be established by the regulating body and provided to all generators in the system. This approach does not necessarily guarantee that a specific capacity target is achieved, but it provides a fixed revenue stream andmay be more straightforward to implement than a capacity market.

The market policies utilized by a number of RTOs in the United States are outlined in Table 1. Similar policies are also in place or under consideration in other parts of the world(Platts, 2014). These mechanisms were originally adopted to meet the peak load challenge of ensuring the availability of sufficient capacity to meet demand during periods of peak load. They also help to ensure long-term resource sufficiency by providing appropriate incentives for investments in new generation capacity. While they were not originally implemented in response to the system challenges presented by VERs, the growth of renewables may make them more important for guaranteeing system reliability. One exception to this is the ORDC system that was recently enacted by ERCOT. This system was designed, in part, to address operational complications brought on by increased VER penetration, as wind forecasting errors are explicitly accounted for in the formulation of the reserves demand curve. The impact of VERs is also driving the push for additional capacity mechanisms in Europe(Platts, 2014).

Table 1: Overview of the different scarcity mechanisms and capacity markets utilized by the eight major electricity market operators in the U.S. For a detailed account of the scarcity pricing policies in each system see (Ela et al., 2014; FERC, 2014). For a detailed account of capacity market practices in ISO-NE, NYISO and PJM see (FERC, 2013), for MISO see (MISO, 2014). 
In this paper, we present a quantitative assessment of the three previously discussed market policies, ORDC, FRSP, and CP to determine their impact on long-term resource and revenue sufficiency in an electricity system with increasing wind generation. A wide body of previous work has identified this capacity adequacy challenge and the general need for innovative market design to address these issues (Hogan, 2005; Joskow, 2007; Stoft, 2002).Moreover, the need for new market design specifically to support increased wind penetration is also discussed in recent literature (Newbery, 2010; Steggals et al., 2011), asit is well known that systems with high levels of renewable generation will likely experience decreased wholesale electricity prices in the short-run (Würzburg et al., 2013), thereby reducing investment incentives for thermal generating units. Some of the work on investment incentives has focused on comparing various proposed market designs that may be implemented to ensure resource adequacy (Batlle and Rodilla, 2010; Cramton and Stoft, 2006). Some literature focuses more specifically on capacity markets (Cramton et al., 2013; Finon et al., 2008; Griffes, 2014; Joskow, 2013, 2008), while other literature has focused on methods to secure resource adequacy through scarcity pricing mechanisms (Hogan, 2012; Schubert et al., 2006). A hybrid structure has also been proposed, with a forward capacity market that provides an annual capacity payment based on the revenue potential of a hypothetical peaking unit, and a day-ahead and real-time scarcity pricing framework(Sener, 2013a, 2013b). Various experiences with capacity markets have also been detailed, e.g. in South Korea (Kim and Kim, 2012), Russia (Boute, 2012), and the United States (Bowring, 2008; FERC, 2013; Spees et al., 2013).The impact of increasing wind penetration on investment incentives for new thermal generators has also been studied in Germany (Traber and Kemfert, 2011). Several case study analyses of the state of Texas have shown that an energy-only market is not sufficient to support reliability targets without greater availability of demand response (Newell et al., 2012), that increasing wind penetration reduces wholesale prices and increases reserve requirements (Zarnikau, 2011), and reduces revenues for natural-gas units (Woo et al., 2012). It has also been suggested that under certain market 
mechanisms, increasing wind penetration may skew investments towards less flexible generators (Di Cosmo and Malaguzzi Valeri, 2014).

This paper expands upon previous literature by conducting a detailed quantitative comparison of three relevant market design options (ORDC, FRSP, and CP) in the context of U.S. electricity markets with increasing wind penetration.Below, we first give a brief overview of the modeling framework. Then we present a case study approximation of the electricity market in Texas (ERCOT), followed by conclusions and directions for future work.

\section{Methodology}

\subsection{Model Formulation}

\subsubsection{Expansion Model}

Threedistinct but related mixed-integer programming (MIP) formulations are utilized to model generation expansion decisions underthe three market policies. These formulations are reviewed briefly below; please see the appendix for more detailed mathematical depictions.

In all cases, the optimization model minimizes the total system-wide cost of developing new thermal generation capacity, servingload and providing spinning-up and non-spinning reserves for a given time period, one year in our analysis. The expansion model, which is an extension of our previous work (Jin et al., 2014; Levin and Botterud, 2015), uses a computationally efficient representation of unit commitment constraints similar to the one in Palmintier and Webster (2014), to model the operation of the power system in detail, considering both unit commitment and dispatch decisions of thermal generators for all the 8760 hours of the year. Wind power is represented by a time series of available wind generation, which may be curtailed in surplus situations, i.e. whenever this is the most cost- 
effective solution. Operating reserve requirements reflect the uncertainty in the wind power forecast, and generally increase with higher wind penetration levels, as further discussed below. Hence, both the variability and uncertainty in the wind resource is considered in the optimal expansion decision. The model is used to find the optimal generation expansion plan for thermal generators (i.e. nuclear, coal, and natural gas fired generation) for a given wind penetration level, accounting for existing resources in the system.

\subsubsection{Prices for Energy and Reserves}

Once the optimal expansion and operational plan is determined, the hourly prices for energy and reserves are found by re-solving the optimization problem with integer variablesfixed, i.e. for expansion and commitment decisions. This corresponds to a linear programming problem, with well-defined shadow prices on system constraints. In each period, the system energy price is calculated from the shadow price of the load balancing constraint, while the prices of spinning-up and non-spinning reserves are also calculated from the shadow prices of their respective constraints (see appendix). As our model co-optimizes generation and reserves, the system energy price is also influenced by the cost of providing reserves. In fact, the energy price in each period can be broken down into four derivative components, the generation cost of the marginal unit in the system, the marginal cost of providing spinning-up reserves, the marginal cost of providing non-spinning reserves, and any costs associated with load curtailment.In the event that load is curtailed, the energy priceis set to the administratively determined the value of lost load (VOLL), which is assumed to be $\$ 9,000 / \mathrm{MWh}$ in our analysis. The resulting energy and reserve prices, along with the capital, fixed and variable costs of generation, are used to calculate the profitability for the individual generation units in the system. 


\subsubsection{Operating Reserve Demand Curve}

The concept of an operating reserve demand curve (ORDC) was born out of the idea that an "Energy

OnlyMarket" - i.e. a system where the revenues from the energy and reserves markets provide sufficient income for generators through appropriate scarcity pricing (Hogan, 2005)to ensure resource adequacywith fewer administrative rules and regulatory mechanisms. This approach values an additional unit of reserves capacity according to the resultant marginal change in the loss of load probability (LOLP) and the assumed VOLL.

On June 1, 2014 ERCOT began implementation of the ORDC system for pricing On-Line and Off-Line Reserve Capacity. Operating hours are divided into four seasonal and six daily bins.ALOLP distribution is generated for each of the bins as a function of reserves levels, based on historical differences between hour-ahead reserve forecasts and the reserves that were available in real-time. Twenty-four individual demand curves are then generated based on these LOLP distributions, the VOLL, a minimum contingency level, and a number of other factors, as outlined in detail by ERCOT (ERCOT, 2013).

We utilize a slightly simplified version of the methodology to generate piecewise linear demand curves for each reserves product that can be easily implemented in our system-wide MIP costminimizationframework (see appendix). Our model includes two distinct reserves products, spinning-up and non-spinning, which correspond withthe On-Line and Off-line reserves products respectively in the ERCOT market. Under the ORDC formulation, reserve capacity is considered to provide a net benefit to the system, which is represented by a negative cost (or positive utility) in the objective function. Both spinning-up and non-spinning reserves provide decreasing marginal benefits as their levels increase.More wind power tends to increase the relative value of both reserves products as the ORDCs are shifted to the right. Regulation reserves and potential spinning-down reserves are not considered in 
Figure 1: Initial spinning-up reserves demand curves that were implemented in ERCOT in June 2014, based on lossof-load probability distributions from historical data for 2011 and 2012(ERCOT, 2013). Each line represents the demand curve for the four hour period beginning with the specified hour. ERCOT maintains a minimum contingency level of $2000 \mathrm{MW}$, therefore the curve can be considered to become vertical at that point.

\subsubsection{Fixed Reserve Scarcity Pricing}

Under the FRSP formulation, target spinning-up and non-spinning reserves levels are identified for each of the 8760 hourly periods being analyzed. These targets are implemented as soft constraints in the MIP. They can be violated, in which case a scarcity event is deemed to occur and a penalty cost is assessed to the system based on the extent of the violation. The target reserves levels used in the case study are determined based on the demand curves that were utilized under the ORDC formulation. This is done by calculating the reserves levels that correspond to an ORDC price of $\$ 15 / \mathrm{MW}-\mathrm{h}$ and $\$ .01 / \mathrm{MW}-\mathrm{h}$ for spinning-up and non-spinning reserves respectively; these are approximately the average prices that result from the ORDC implementation. The scarcity penalties are set to $\$ 100 / \mathrm{MW}-\mathrm{h}$ and $\$ 500 / \mathrm{MW}-\mathrm{h}$ for spinning-up and non-spinning reserves, respectively, these values are based on practice in CAISO(FERC, 2014). In accordance with practices in both ERCOT and CAISO, the non-spinning scarcity penalty is

\footnotetext{
${ }^{1}$ Most US electricity markets do not currently have a market for spinning-down reserves, although this may be introduced to provide downward flexibility as more VERs are introduced(Ela et al., 2011). Our early analysis of the ERCOT system indicated that spinning-down reserves were rarely scarce, particularly with large quantities of wind generation that can be easily curtailed, thereby inherently providing spinning-down reserves. The ORDC in ERCOT does not apply to regulation reserves.
} 
assessed when there is a shortfall in the combined target for spinning-up and non-spinning reserves.Under this formulation, the market clearing prices of the two reserves products are determined by the shadow price of the respective reserves constraints and the energy price is taken from the shadow price of the load balance constraint.See the appendix for additional information on how these prices are determined, how the reserves constraints are formulated, and how the reserves targets are calculated.

\subsubsection{Capacity Payments}

The CP formulation closely mirrors the FRSP formulation, with the addition of a capacity payment term in the objective function. The same reserves constraints are implemented and the same penalty costs for reserve scarcity events are included in the objective function to encourage resource sufficiency. The key difference is that these costs are not included in the market clearing prices of energy or reserves products, under the assumption that the energy and reserve prices are capped at lower levels. The energy and reserve prices are determined from the shadow prices of the relevant constraints, as under the FRSP formulation. However, in periods when a scarcity event occurs, the penalty cost is subtracted out of the shadow prices to obtain the resulting wholesale prices. Therefore, without the inclusion of scarcity pricing in wholesale prices, generators are largely dependent on the capacity payments for the recovery of their fixed investment and operational costs; this is particularly true for those units with higher marginal costs of generation.In most markets with capacity payment mechanisms, the capacity price is set according to the clearing price ofa capacity auction held several years in advance of the target commitment period. We assume a fixed $\$ 40 / \mathrm{kW}$-year capacity payment for our analysis. This amount is in line with historical results from markets that are currently operating in the U.S. (FERC, 2013), although prices do vary from market to market and year to year. For comparison, the annualized capital investment cost of NGCT unit, which has the lowest such cost of the technologies considered in our analysis, is $\$ 52 / \mathrm{kW}$-year. 


\section{Case Study}

\subsection{System Assumptions}

The assumptions of the electric power system considered in our analysis are roughly based on the ERCOT system. However, due to a number of simplificationswe wish to be clear that our results are not intended to provide a detailed analysis of the actual ERCOT system.Rather, these results should primarily be interpreted in terms of the relative changes that are observed as wind levels increase, as the absolute results are dependent on a range of uncertain system assumptions. The generation portfolio of the modeled system includes four different thermal unit types, nuclear, coal, natural gas combined cycle (NGCC), and natural gas combustion turbine (NGCT). The existing capacities of these generator types are based on ERCOT 2015 summer capacity projections (ERCOT, 2014). Because the aggregated ERCOT data do not distinguish between types of natural gas units, EIA form-860 data are used to approximate the natural gas breakdown between NGCC and NGCT units(EIA, 2013).

The cost and operating parameters of these thermal generators are taken from the 2014 AEO (EIA, 2014a)while capacity is de-rated according to NEMS forced outage rates (EIA, 2014b).

Cost and operating parameters for wind generators are taken from the 2013 Wind Technologies Market Report, which provides detailed wind specific data(Wiser and Bolinger, 2014). Interest rates used to annualize the overnight investment costs of new generation capacity are based on the values used for levelized cost of electricity calculations in the 2014 Annual Energy Outlook(EIA, 2014c)

The load profile is based on ERCOT 2013 hourly load data which are scaled up to the peak demand forecast in 2024 (15\% growth) (ERCOT, 2014). All scenarios assume the availability of $1200 \mathrm{MW}$ of spinning-up reserves capacity from demand side resources based on historical ERCOT data (ERCOT, 2015). The hourly wind profile is also based on 2013 ERCOT data which are scaled in accordance with 
the assumed total system wind capacity for each model run. In 2013 wind generation served roughly $10 \%$ of total load in the ERCOT system. We analyze wind penetration scenarios varying from $10 \%$ to $40 \%$, where $10 \%$ wind penetration means that there exists sufficient wind generation to serve $10 \%$ of annual demand in the system. The baseline natural gas fuel price is $\$ 5.15$ in 2012 dollars based on EIA AEO projections for the electric power sector in the West South Central region for 2024 (EIA, 2014d). Additional sensitivity analyses around different natural gas fuel prices are also performed.

Our baseline scenarios assume the existence of a $\$ 23 / \mathrm{MWh}$ PTC for all wind generation. It is also assumed that wind generators are able to provide spinning-up reserves by curtailing their generation. We conduct a sensitivity analysis to examine alternatives to these assumptions for wind power.

Table 2: Generating unit parameters

Table 3: System parameters

\section{Results and Discussion}

\subsection{Market Policies}

We first compare the impacts of increasing wind penetration in systems operating under the three different market policies that have been discussed, ORDC, FRSP and CP.

\subsubsection{Expansion}

Under all three market policies, only new NGCT capacity is developed. This is due to a variety of factors including the existing generation portfolio, the cost of each expansion alternative, and the need for 
system flexibility, which is best provided by NGCT units. Figure 2 illustrates that more capacity is developed when a $\$ 40 / \mathrm{kW}$ capacity payment is allocated to new capacity, due to the direct capacity incentive. The FRSP policy also results in slightly more new capacity being developed than the ORDC policy. This might be expected, as the FRSP framework provides a strong disincentive to avoid reserve shortfalls through the application of a relatively large penalty for each unit of reserve scarcity, regardless of the extent of the shortfall. In contrast, the unit cost to the system for a similar small reduction in reserves under the ORDC formulation is correspondingly small. As a result, additional capacity is developed under the FRSP policy in order to avoid costly shortfall penalties during peak hours. Overall, less new capacity is required for higher levels of wind penetration as the availability of wind generation decreases total net load over the course of the year.However, when wind penetration increases from $10 \%$ to $40 \%$ (from $13,179 \mathrm{MW}$ to $52,714 \mathrm{MW}$ of wind capacity), peak net load only decreases by $5 \%$ (from 74,775 MW to 71,283 MW), as the peak net load hour shiftsto a different summer day with less wind generation ${ }^{2}$. The reductions in new thermal generation capacity as the system progresses from $10 \%$ to $40 \%$ wind penetrationunder each policy, 3,570 MW, 3,360 MW and 3,150 MW for ORDC, FRSP and $\mathrm{CP}$ respectively, roughly correspond with this 3,492 $\mathrm{MW}$ reduction in peak load.

Figure 2:New NGCT capacity with increasing wind under each market policy

\subsubsection{Energy and Reserves Prices}

Figure 3 shows the average system energy price for each policy and $10 \%, 20 \%, 30 \%$ and $40 \%$ wind penetration broken out into its contributing components: the marginal cost of generation, the marginal cost of spinning-up and non-spinning reserves and the cost of lost load events. As energy and reserves are co-optimized, the marginal cost of providing each reserves product contributes to the total energy price in each period when the reserve constraints are binding. The components of the energy price that

\footnotetext{
${ }^{2}$ Based on 2013 ERCOT historical wind and load profiles.
} 
are attributable to the provision of spinning-up and non-spinningreserves are therefore also equal to the average prices of each reserves product.

The average system energy price drops with increasing wind under all three policies. This is largely due to the fact that coal and wind units increasingly provide the marginal unit of generation as wind penetration increases, primarily displacing NGCC units with higher variable costs. This effect is also illustrated in Figure 4. The marginal cost of wind generation is negative $(-\$ 23 / \mathrm{MWh})$ due to the PTC, since wind generators would be willing to pay money in order to generate so that they can claim the tax credit. The reserves prices -and correspondingly, their contribution to the energy price - do generally increase with increasing wind penetration, however this effect is not as strong as the reduction in marginal cost of generation and therefore the net shift in energy prices is negative.While the average marginal costs of generation alone are comparable across all three policies, average energy prices are higher under the FRSP policy ${ }^{3}$ than they are under the ORDC policy, and lower under the CP policy.

In the case of the FRSP policy, this higher energy price is generally dictated by reserves scarcity events, which occur when the soft reserves constraints are violated and a penalty is assessed. Because these events result in price spikes (an increase of $\$ 100 / \mathrm{MWh}$ or $\$ 500 / \mathrm{MWh}$ ) a relatively modest increase in their frequency can have a large impact on overall average energy prices.

Because the CP policy provides no administrative mechanism to price the cost of reserves scarcity, average energy prices are much lower. A small reserves price remains due to the opportunity cost of providing reserves when the system is otherwise constrained.

In the event that there is insufficient generation to serve demand, load is curtailed and the system energy price is set to the administrative determined value of lost load (VOLL), which is $\$ 9,000 / \mathrm{MWh}$.

\footnotetext{
${ }^{3}$ The energy prices resulting from a FRSP policy are highly dependent on the specific scarcity penalty values that are chosen. These results should not be interpreted to suggest that a FRSP approach will always result in higher energy prices than the ORDC approach.
} 
Therefore, when averaged over the 8,760 hours in a year, each lost load event increases the average annual energy price by roughly $\$ 1 / \mathrm{MWh}$. In the scenarios analyzed, lost load events occur in anywhere from zero to seven hours per year, and have a noticeable contribution to the average annual energy price (Figure 3) despite the fact that they are essentially imperceptible in Figure 4. This is because of the high VOLL. Load curtailment is more frequent under the ORDC policy that the FRSP policy due to the fact that less new capacity is developed. However, the impact that load curtailment has on average prices is not as significant as the impact from reserve scarcity events. Under the CP policy there are no lost load events for up to $30 \%$ wind penetration, and only a single event for $40 \%$ wind penetration. This is due to the additional generation capacity that is developed under the CP policy.

Figure 3:Components of average energy price with increasing wind under each market policy

Figure 4:Fraction of time as marginal unit with increasing wind under each market policy

Figures 5 and 6 show the energy price exceedance curves for each policy with $10 \%$ and $40 \%$ wind penetration respectively. These depict the fraction of hours during which energy prices exceed a given value. The impact of the ORDC approach is clearly evident, as the system energy price assumes a more continuous spectrum of intermediate prices. This contrasts the more discrete step function that is obtained when a soft reserves constraint is utilized, which is characterized by price spikes due to reserve scarcity events. As a result, while the average energy price is comparable between the two policies, the energy price exceeds $\$ 100 /$ MWhduring 1018 hours per year under FRSP, compared to just 143 hours per year under the ORDC policy with $10 \%$ wind penetration, and 823 hours versus 92 hours with $40 \%$ 
wind penetration. There is far less variability under the capacity payment policyas there is no mechanism for pricing reserves scarcity, and energy prices are effectively capped at the highest marginal cost of generation plus any internal opportunity costs associated with meeting the reserves constraints, unless load curtailment occurs. The energy price never exceeds $\$ 100 / \mathrm{MWh}$ with $10 \%$ wind penetration and does so during only a single hour with $40 \%$ wind penetration when load is curtailed and the energy price is set to $\$ 9,000 / \mathrm{MWh}$.

Figure 5:Energy price exceedance curves with $10 \%$ wind penetration under each market policy

Figure 6:Energy price exceedance curves with $40 \%$ wind penetration under each market policy

Many RTOs in the United States have traditionally calibrated their planning reserve margins to satisfy the "one day in ten year" criterion, which dictates that load curtailment should not exceed one day in ten years (2.4 hours per year). It has, however, been argued that adherence to this metric results in more conservative system capacity than is economically optimal(Cramton and Stoft, 2006; Wilson, 2010). Our results indicate a slightly more frequent occurrence of lost load under the ORDC policy (5-7 hours per year depending on wind penetration), comparable occurrence under FRSP policy (2-4 hours per year), and less frequent occurrence under CP (0-1 hours per year). These results do suggest that the one in ten metric may be slightly more conservative than what is economically optimal in a market with continuous reserves scarcity pricing, based on the current valuation of lost load in ERCOT. 


\subsubsection{Generator Profits}

Figure 7 shows the average profit for each type of generator as a function of wind penetration under each policy. In general, average profit drops for baseload and wind generators with increasing wind penetration under all policies. This is primarily due to the reductions in average energy price that occur for reasons discussed previously. These technologies generate electricity throughout all periods of the day and are therefore more exposed to depressed prices during off-peak hours. The profits for NGCC and NGCT units are generally more consistent as wind penetration increases. These technologies provide a larger share of their generation during peak periods where energy prices tend to remain high even with increasing wind penetration. They also receive an additional revenue stream from the increased demand for reserves and increasing reserves prices.NGCT units for example, receive $26 \%$ of their total revenue from providing reserves with $40 \%$ wind penetration. Profits for wind units decrease under all scenarios as wind penetration increases, as they are also affected by the trend towards lower average system energy prices. At higher penetration levels, wind units do also receive additional revenue from providing more reserves (during curtailment), but this effect is not as large as the lost revenue due to lower energy prices.

All of these calculations assume that all generators are still exposed to an annualized capital investment cost; the economics would change significantly for units that are no longer making capital payments. For example, old nuclear and coal units that have already paid down their original capital investments would see their average profits increased by $\$ 374 / \mathrm{kW}$-year and $\$ 297 / \mathrm{kW}$-year respectively, making both technologies profitable under these market policies, even when wind penetration reaches $40 \%$ (Figure 8). However, investments in new plants would clearly not be profitable without additional incentives.We assume that wind units do receive capacity payments for $8.7 \%$ of their installed capacity, in accordance with current practices in ERCOT (ERCOT, 2014). 
Figure 7:Average profit for each generation technology with increasing wind under each market policy

\author{
Figure 8: Average profit for each generation technology without capital costs with increasing wind under each \\ market policy
}

\title{
4.2 Sensitivities
}

The previous section demonstrated that the FRSP market policy leads to more frequent spikes in the system energy price, while the ORDC approach generates a smoother, less variable continuum of prices. This reduction in price variability reduces risk for generators, who are otherwise reliant on high prices during relatively few operating hours to recover their fixed costs. We therefore choose the ORDC approach as our baseline for analyzing the potential impacts of two different policies impacting wind generation and a range of potential natural gas prices.

\subsubsection{Wind Policies}

Our first sensitivity analysis examines the impact of eliminating the $\$ 23 / \mathrm{MWh}$ PTC that is currently provided to wind generators.All wind projects that commenced construction prior to January 1, 2015 are eligible for this credit for all electricity that they generate during the first ten years of their operation. Under the current status quo, the credit will not apply to any project that has or will commence operation on or after January 1, 2015. While the credit has been extended a number of times previously, and sometimes retroactively, there isa possibility that another extension will not be forthcoming. The second sensitivity assumes that wind generators are not able to provide spinning-up reserves when their generation has been curtailed. 
Changes in these policies do not have any material impact on expansion decisions ${ }^{4}$; however they do affect system energy prices and generator revenues. Eliminating the PTC will clearly reduce the revenue of wind generators, but it also has the secondary impact of increasing energy prices throughout the entire system (Figure 9). This occurs since the marginal generation cost of wind increases from $\$ 23 / \mathrm{MWh}$ to $\$ 0 / \mathrm{MWh}$. Therefore, during periods when wind is providing the marginal unit of generation, an increasingly common occurrence as wind penetration increases, the energy price in that period will increase by $\$ 23 / \mathrm{MWh}$ compared to the baseline scenario.In contrast, if wind generators are not able to provide spinning-up reserves when their generation is curtailed, average energy prices decrease.In this situation, the average marginal cost of generation in the system actually increases slightly, as wind provides the marginal unit of generation less frequently; however this effect is overshadowed by a decreasing cost of spinning-up reserves. This occurs because more NGCC units are being committed to provide spinning-up reserves in the place of wind. Once a unit is committed, its full excess capacity is allocated to provide up reserves at no additional cost. Therefore more reserves are provided, which causes a downward shift in prices in accordance with the reserves demand curve. The additional capacity that is committed for NGCC units also frees up capacity at coal units to provide more low-cost generation instead of reserves. Neither of these effects are present to any significant extent until wind penetration reaches $30 \%$, as can be seen in Figure 9.

Figure 9:Components of average energy price with increasing wind under each wind policy

Figure 10 shows the changes in average profits for each generation technology under each wind policy, relative to the baseline scenario. Baseload units benefit from the increasing average energy prices experienced when the PTC is removed and see their profits decrease when wind generators cannot

\footnotetext{
${ }^{4}$ These modeling results are not detailed here in the interest of brevity. Recall that the development of new wind capacity is an exogenous input to the model.
} 
provide reserves in accordance with the lower energy prices that result. The profits of NGCT peaking plants are relatively unaffected by either wind policy, while NGCC units show some small change in revenue for high wind levels. Unsurprisingly, wind profits decrease significantly when the PTC is eliminated, however this effect diminishes somewhat with increasing wind penetration as a larger share of their revenue comes from providing reserves. Similarly, when wind units are no longer permitted to provide reserves, profits are relatively unaffected for low levels of wind penetration but begin to decrease as wind penetration increases and the units can no longer generate revenue by providing reserves when they are curtailed.

Figure 10:Average profit for each generation technology relative to baseline for the No PTC and No Wind Reserves scenarios.

\subsubsection{Natural Gas Prices}

The price of natural gas is a significant factor in the profitability of all generation units, not just those that use natural gas as a fuel source. As was illustrated in Figure 4, NGCC units provide the marginal unit of generation more than any other unit, and therefore the marginal cost of generation of these units is a major driver of the system energy price. We now analyze the impact ofvarying natural gas prices from the baseline value of $\$ 5.15$ to $\$ 3, \$ 8, \$ 10$ and $\$ 12$ per million btu (MMbtu).

When the natural gas price is reduced to $\$ 3 / \mathrm{MMbtu}$ there is no change in investment decisions, as natural gas-fired units are already cost-effective at the baseline cost of $\$ 5.15 / \mathrm{MMbtu}$. At a natural gas price of $\$ 8 / \mathrm{MMbtuthere} \mathrm{is} \mathrm{also} \mathrm{no} \mathrm{change} \mathrm{in} \mathrm{expansion} \mathrm{decisions} \mathrm{compared} \mathrm{to} \mathrm{the} \mathrm{baseline} \mathrm{case.} \mathrm{When}$ the price reaches $\$ 10 / \mathrm{MMbtunew}$ nuclear units are developed with $10 \%$ wind, and new coal units are developed with higher wind levels due to the small amount of flexibility and reserves they are able to provide. Some new NGCT units are developed with $20 \%$ wind and with $30 \%$ and $40 \%$ NGCT unit 
expansion is the same as under baseline conditions. At a price of $\$ 12 / \mathrm{MMbtu}$, additional nuclear and coal units are developed and existing NGCC and NGCT units are committed and dispatched less frequently due to their increased variable cost.Some new NGCT units are developed when wind penetration reaches $40 \%$, but not to the same extent as occurs with lower natural gas prices.

Figure 11:New capacity of each generation technology that is developed with increasing wind and across a range of natural gas prices

Figure 12 shows that average energy prices generally increase with increasing natural gas prices, particularly with higher levels of wind penetration. These increasing energy prices are due to increases in both the marginal cost of generation and the marginal cost of reserves provision. Higher natural gas prices also lessen the depression of energy prices caused by increasing wind penetration. For example, with the baseline natural gas price of $\$ 5.15 / \mathrm{MMbtu}$, the average system energy price decreases by $28 \%$ when wind penetration increases from $10 \%$ to $40 \%$. There is similarly a $31 \%$ decrease when the natural gas price is $\$ 3 / \mathrm{MMbtu}$. In contrast, when the natural gas price is $\$ 12 / \mathrm{MMbtu}$ this decrease is only $4 \%$, and when the price is $\$ 10 / \mathrm{MMbtu}$ there is actually a $4 \%$ increase in the average price. This is a result of the increased cost of providing reserves when natural gas prices are high, as well as more frequent incidence of lost load events, both of which contribute to higher average energy prices.

Figure 12:Components of average energy price with increasing wind under a range of natural gas prices

Figure 13 shows that the increased energy prices caused by high natural gas prices make nuclear and coal units more profitable. In fact, when the price reaches $\$ 12 / \mathrm{MMbtu}$, both nuclear and coal units can actually generate a small net profit in some situations, even when considering their annualized 
investment cost outlay. Conversely, when the price falls to $\$ 3 / \mathrm{MMbtu}$, both baseload units see their profitability reduced. In general, profits for wind generators tend to increasewith increasing natural gas prices.Profits for NGCT and NGCC units are relatively consistent when the natural gas price is either $\$ 3$, $\$ 5.15$ or $\$ 8 /$ MMbtubut they decrease somewhat for higher gas prices and low wind levels. This is not surprising, as no gas-fired generation is built in those cases (Figure 11). When wind penetration is high, new NGCT capacity is always built and theprofits of both NGCT and NGCC units are relatively unchanged compared to baseline, even with high natural gas prices, due largely to additional revenues from providingreserves.

Figure 13:Average profit for each generation technology relative to baseline $(\$ 5.15 / \mathrm{MMbtu})$ for a range of natural gas prices.

\section{Conclusion and Policy Implications}

We have investigated the ability of three different market mechanisms (ORDC, FRSP, CP) to provide resource adequacy and generator revenue sufficiency in electricity markets with increasing amounts of renewable energy. In a case study of ERCOT, we find that under base assumption NGCT plants constitute the only new generation capacity in the system under all three policies. However, the amount of generation expansion and the implications for prices and profitability differ.

Of the three policies, the least generation capacity is developed under the ORDC framework, 5,460 MW with $10 \%$ wind penetration and 1,890 MW with $40 \%$ wind penetration. Under the FRSP policy 5,880 MW and 2,520MW of new NGCT capacity are developed for $10 \%$ and $40 \%$ wind respectively. Average energy prices are slightly greater under than FRSP framework than those obtained with an ORDC primarily due 


\begin{abstract}
The relative profitability of each generation technology when compared between policies follows the same general trend as average energy prices. Capacity payments provide an additional revenue stream for generators, however when fixed at $\$ 40 / \mathrm{kW}$, they are not as substantial as the additional revenue associated with higher energy and revenue prices that occur when there is a market mechanism (FRSP or ORDC) to explicitly value reserve scarcity. Therefore average profits are the lowest for all generation technologies under the CP policy.
\end{abstract}

Generator revenues for nuclear, coal and wind units decrease with increasing wind levels across all three policies, while NGCC and NGCT units are less susceptible to this effect. New nuclear and coal units are unlikely to be built, but existing units that have paid off their capital investments may still remain profitable. Natural gas generators provide a larger share of their generation during peak periods when energy prices remain high and are therefore less exposed to the broader energy price reductions that occur disproportionately during baseload hours. These generators also obtain alarger share of their total revenue from providing reserves as the demand for and price of these products increase with increasing wind penetration.Our results also indicate that surplus capacity is built under the assumed $\$ 40 / \mathrm{kW}$-year capacity payment, further depressing energy and reserve prices. This suggests that a lower payment may be sufficient to achieve capacity adequacy. However, a higher payment is required to ensure revenue sufficiency for individual generators when reserve scarcity is not reflected in energy and reserve prices. This discrepancy can be attributed to the fact that the optimal expansion plan is determined on 
the basis of minimizing the total cost of serving load in the system as opposed to maximizing generator profits.

In a sensitivity analysis, we found that the PTC has a significant impact on the revenue generated by wind generators. Similarly, wind generators are increasingly dependent on revenue from providing reserves as windpenetration increases. Eliminating their ability to provide spinning-up reserves when their generation is curtailed also reduces their profitability. As the cost of natural gas increases, so do the average system energy price and the profitability of wind and baseload generators. Natural gas powered generating units see a reduction in their profitability due to increased costs, but these effects are tempered as wind penetration increases and revenues from reserves provision increase. New coal and nuclear units are developed when natural gas prices reach $\$ 10 / \mathrm{MMbtu}$ and wind penetration is $10 \%$ or $20 \%$, and are similarly developed for all wind levels when gas prices reach $\$ 12 / \mathrm{MMbtu}$. If the price of natural gas falls to $\$ 3 / \mathrm{MMbtu}$ nuclear and coal units become less profitable due to lower energy prices. There is no change in investment decisions as natural gas-fired units only become even more cost-effective with the lower fuel price.

We show that an ORDC implementation can be structured to result in comparable optimal unit expansion plans and generator revenues as a FRSP approach. However, the ORDC policy leads to a more continuous spectrum of hourly reserves and energy prices, whereas the FRSP framework results in a more discrete spectrum of energy prices and frequent price spikes when scarcity events occur. Generators are therefore reliant on the price spikes in these scarcity periods to recover their fixed costs. These price spikes are difficult to justify from a reliability perspective, since a small and large reserve shortfall leads to the same marginal penalty. They are also a source of additional investment and operational risk for all generators, particularly flexible units, and may contribute to concerns over potential market manipulation. Alternatively, under the ORDC policy, the costs of reserves under 


\section{Acknowledgements}

The authors acknowledge the U.S. Department of Energy, Office of Energy Efficiency and Renewable Energy through its Wind and Water Power Program for funding the research presented in this paper. The submitted manuscript has been created by UChicago Argonne, LLC, Operator of Argonne National Laboratory ("Argonne"). Argonne, a U.S. Department of Energy Office of Science laboratory, is operated under Contract No. DE-AC02-06CH11357. 


\section{References}

Batlle, C., Rodilla, P., 2010. A critical assessment of the different approaches aimed to secure electricity generation supply. Energy Policy, Energy Efficiency Policies and Strategies with regular papers. 38, 7169-7179. doi:10.1016/j.enpol.2010.07.039

Boute, A., 2012. Promoting renewable energy through capacity markets: An analysis of the Russian support scheme. Energy Policy 46, 68-77. doi:10.1016/j.enpol.2012.03.026

Bowring, J.E., 2008. Chapter 10 - The Evolution of PJM's Capacity Market, in: Sioshansi, F.P. (Ed.), Competitive Electricity Markets, Elsevier Global Energy Policy and Economics Series. Elsevier, Oxford, pp. 363-386.

Cramton, P., Ockenfels, A., Stoft, S., 2013. Capacity Market Fundamentals. Economics of Energy and Environmental Policy 2, 27-46.

Cramton, P., Stoft, S., 2006. The Convergence of Market Designs for Adequate Generating Capacity with Special Attention to the CAISO's Resource Adequacy Problem (White Paper).

Di Cosmo, V., Malaguzzi Valeri, L., 2014. The incentive to invest in thermal plants in the presence of wind generation. Energy Economics 43, 306-315. doi:10.1016/j.eneco.2014.03.009

EIA, 2014a. Assumptions to AEO2014: Electricity Market Module. Energy Information Administration.

EIA, 2014b. Annual Energy Outlook 2014 NEMS Documentation: Renewable Fuels Module. Energy Information Administration.

EIA, 2014c. Levelized Cost and Levelized Avoided Cost of New Generation Resources in the Annual Energy Outlook 2014. Energy Information Administration.

EIA, 2014d. Annual Energy Outlook 2014: Supplemental Table 17. Energy Information Administration.

EIA, 2013. Form EIA-860 Detailed Data. Energy Information Administration.

Ela, E., Milligan, M., Bloom, A., Botterud, A., Townsend, A., Levin, T., 2014. Evolution of Wholesale Electricity Market Design with Increasing Levels of Renewable Generation (Technical Report No. NREL/TP - 5D00 - 61765). National Renewable Energy Laboratory.

Ela, E., Milligan, M., Kirby, B., 2011. Operating Reserves and Variable Generation (No. TP-5500-51978). National Renewable Energy Laboratory, Golden, CO.

ERCOT, 2015. Historical Real-Time Reserve Prices Based on ORDC for 15-minute Settlement Interval.

ERCOT, 2014. Report on the Capacity, Demand, and Reserves in the ERCOT Region. Electricity Reliability Council of Texas.

ERCOT, 2013. Methodology for Implementing Operating Reserve Demand Curve (ORDC) to Calculate Real-Time Reserve Price Adder. Fifth Draft. 
FERC, 2014. Staff Analysis of Shortage Pricing in RTO and ISO Markets (No. Price Formation in Organized Wholesale Electricity Markets: Docket No. AD14-14-000). Federal Energy Regulatory Commission, Washington, DC.

FERC, 2013. Centralized Capacity Market Design Elements (No. Commission Staff Report AD13-7-000). FERC.

Finon, D., Meunier, G., Pignon, V., 2008. The social efficiency of long-term capacity reserve mechanisms. Utilities Policy, Capacity Mechanisms in Imperfect Electricity Markets 16, 202-214. doi:10.1016/j.jup.2008.01.001

Griffes, P.H., 2014. Renewable Generation and Capacity Markets. IAEE Energy Forum.

Hogan, W.W., 2012. Electricity Scarcity Pricing Through Operating Reserves: An ERCOT Window of Opportunity (White Paper).

Hogan, W.W., 2005. On an "Energy Only" Electricity Market Design for Resource Adequacy. white paper, Harvard University.

Jin, S., Botterud, A., Ryan, S.M., 2014. Temporal Versus Stochastic Granularity in Thermal Generation Capacity Planning With Wind Power. IEEE Transactions on Power Systems 29, 2033-2041. doi:10.1109/TPWRS.2014.2299760

Joskow, P.L., 2013. Symposium on “Capacity Markets." Economics of Energy and Environmental Policy 2, v-vi.

Joskow, P.L., 2008. Capacity payments in imperfect electricity markets: Need and design. Utilities Policy, Capacity Mechanisms in Imperfect Electricity Markets 16, 159-170. doi:10.1016/j.jup.2007.10.003

Joskow, P.L., 2007. Competitive Electricity Markets and Investment in New Generating Capacity. The New Energy Paradigm(Dieter Helm, Editor), Oxford University Press.

Kim, H., Kim, S.-S., 2012. The resource adequacy scheme in the Korean electricity market. Energy Policy 47, 133-144. doi:10.1016/j.enpol.2012.04.035

Levin, T., Botterud, A., 2015. Capacity Adequacy and Revenue Sufficiency in Electricity Markets With Wind Power. IEEE Transactions on Power Systems 30, $1644-1653$. doi:10.1109/TPWRS.2015.2403714

MISO, 2014. Business Practice Manual: Resource Adequacy (No. BPM-011-r13). Midcontinent Transmission System Operator.

Newbery, D., 2010. Market design for a large share of wind power. Energy Policy, Large-scale wind power in electricity markets with Regular Papers 38, 3131-3134. doi:10.1016/j.enpol.2009.07.037

Newell, S., Spees, K., Pfeifenberger, J., Mudge, R., DeLucia, M., Carlton, R., 2012. ERCOT Investment Incentives and Resource Adequacy. The Brattle Group, Cambridge, Massachusetts. 
Platts, 2014. EU Electricity: Capacity Mechanisms.

Schubert, E.S., Hurlbut, D., Adib, P., Oren, S., 2006. The Texas Energy-Only Resource Adequacy Mechanism. The Electricity Journal 19, 39-49. doi:10.1016/j.tej.2006.11.003

Sener, A.C., 2013a. A Hybrid Resource Adequacy Compensation Mechanism. The Electricity Journal 26, 36-41. doi:10.1016/j.tej.2013.09.015

Sener, A.C., 2013b. Texas's Energy-only Resource Adequacy Paradox. The Electricity Journal 26, 22-33. doi:10.1016/j.tej.2013.04.004

Shanker, R.J., 2003. Comments of Roy J. Shanker, Ph.D. On Standard Market Design: Resource Adequacy Requirement. Federal Energy Regulatory Commission, Submittal 20030110-5081, Docket Number RM01-12-000.

Spees, K., Newell, S.A., Pfeifenberger, J.P., 2013. Capacity Markets - Lessons Learned from the First Decade. Economics of Energy and Environmental Policy 2, 1-26. doi:10.5547/2160-5890.2.2.1

Steggals, W., Gross, R., Heptonstall, P., 2011. Winds of change: How high wind penetrations will affect investment incentives in the GB electricity sector. Energy Policy 39, 1389-1396. doi:10.1016/j.enpol.2010.12.011

Stoft, S., 2002. Power System Economics. IEEE Press, Piscataway, NJ, USA.

Traber, T., Kemfert, C., 2011. Gone with the wind? - Electricity market prices and incentives to invest in thermal power plants under increasing wind energy supply. Energy Economics 33, 249-256. doi:10.1016/j.eneco.2010.07.002

Wilson, J.F., 2010. Reconsidering Resource Adequacy, Part 1. Public Utilities Fortnightly.

Wiser, R., Bolinger, M., 2014. 2013 Wind Technologies Market Report. Lawrence Berkeley National Laboratory.

Woo, C.-K., Horowitz, I., Horii, B., Orans, R., Zarnikau, J., 2012. Blowing in the Wind: Vanishing Payoffs of a Tolling Agreement for Natural-gas-fired Generation of Electricity in Texas. The Energy Journal 33, 207-229. doi:10.5547/ISSN0195-6574-EJ-Vol33-No1-8

Würzburg, K., Labandeira, X., Linares, P., 2013. Renewable generation and electricity prices: Taking stock and new evidence for Germany and Austria. Energy Economics, Supplement Issue: Fifth Atlantic Workshop in Energy and Environmental Economics 40, Supplement 1, S159-S171. doi:10.1016/j.eneco.2013.09.011

Zarnikau, J., 2011. Successful renewable energy development in a competitive electricity market: A Texas case study. Energy Policy, Special Section: Renewable energy policy and development 39, 3906-3913. doi:10.1016/j.enpol.2010.11.043

Zhou, Z., Botterud, A., 2014. Dynamic Scheduling of Operating Reserves in Co-Optimized Electricity Markets With Wind Power. IEEE Transactions on Power Systems 29, 160-171. doi:10.1109/TPWRS.2013.2281504 


\section{Appendix}

\subsection{Notation}

Indices

I: Set of all of generation unit types

$T$ : Set of all time periods

\section{Decision Variables}

$u_{i}$ : Expansion variable, number of units of plant type $i$ constructed (integer)

$x_{i, t}$ : Shut-down variable, number of units of plant type $i$ shut down during period $t$ (integer)

$y_{i, t}$ : Start-up variable, number of units of plant type $i$ started up during period $t$ (integer)

$z_{i, t}$ : Commitment variable, number of units of plant type $i$ that are committed during period $t$ (integer)

$g_{i, t}$ : Total generation from plant type $i$ during period $t$

$r s_{i, t}:$ Total spinning-up reserves provided by plant type $i$ during period $t$

$r n s_{i, t}:$ Total non-spinning reserves provided by plant type $i$ during period $t$

$e s_{t}$ : Energy scarcity (lost load) during period $t$

$r s s_{t}$ : Spinning-up reserves scarcity experienced during period $t$

$r n s s_{t}$ :Non-spinning reserves scarcity experienced during period $t$

$w g_{t}$ : Wind generation during period $t$ 
$w c_{t}:$ Wind curtailment during period $t$

$w r_{t}$ : Wind spinning-up reserves provided during period $t$

\section{Parameters}

$C_{i}$ : Annualized capital cost of plant type $i$

$F_{i}$ : Fixed operating cost of plant type $i$

$M C_{i}$ : Marginal generation cost of plant type $i$, including fuel and variable O\&M

$S U C_{i}:$ Start-up cost of plant type $i$

$S D C_{i}$ : Shut-down cost of plant type $i$

$N L C_{i}$ : No load cost of plant type $i$

$R U_{i}$ : Maximum ramp-up of plant type $I$ in one time period

$R D_{i}$ : Maximum ramp-down of plant type ïn one period

$\overline{P_{i}}:$ Capacity of plant type $i$

$\overline{O_{i}}$ : Maximum generation and spinning reserves output of plant type $i$. This is typically assumed to be slightly lower than $\overline{P_{i}}$ due to unit de-rating for forced outages.

$\underline{O_{i}}:$ Minimum generation output of plant type $i$

$S P R_{i}$ : Maximum fraction of committed capacity at plant type ithat can provide spinning-up reserves

$N S R_{i}$ : Maximum fraction of uncommitted capacity at plant type ithat can provide non-spinning reserves

$D_{t}:$ System energy demand in period $t$ 
$W_{t}$ : Wind resource availability in period $t$

$R s_{i, t}$ : Total system contribution to the spinning-up ORDC in period $t$

$R n s_{i, t}$ : Total system contribution to the non-spinning ORDC in period $t$, includes spinning-up reserves

$R R s_{t}:$ Spinning-up reserve requirement in period $t$

$R R n s_{t}$ : Non-spinning reserve requirement in period $t$

$R B S_{t}\left[R s_{t}\right]$ : Spinning reserve benefit during period $t$, piecewise linear function of spinning reserve level

$R B N S_{t}\left[R n s_{t}\right]$ : Non-spinning reserve benefit during period $t$, piecewise linear function of total spinning and non-spinning reserve levels

VOLL: Value of lost load

SRSC: Spinning-up reserve scarcity cost for relaxation of the spinning reserves constraint in the FSPR and CP formulations.

$N R S C$ :Non-spinning reserve scarcity cost for relaxation of the soft non-spinning reserves constraint in the FSPR and CP formulations.

$C P$ : Capacity payment

PTC: Production tax credit

\section{ORDC}

Pns: Non-spinning reserve price-adder

Ps: Spinning-up reserve price-adder

VOLL: Value of lost-load 
$\lambda$ : System lambda, shadow price of the power balance constraint

$\mu_{h, m, w}$ : Mean of loss-of-load probability (LOLP) distribution in system during hour $h$, month $m$, and with $w$ percent wind penetration.

$\sigma_{h, m, w}:$ Standard deviation of loss-of-load probability (LOLP) distribution in system during hour $h$, month $m$, and with $w$ percent wind penetration.

$w$ : Wind penetration, annual wind resource availability as fraction of total system demand

rs: Spinning-up reserves in the system

rns: Non-spinning reserves in the system

$X$ : System minimum contingency level for combined spinning-up and non-spinning reserves

\subsection{Mathematical Formulation}

For each of the three market policies, a mixed-integer program (MIP) is solved to determine the lowestcost means of serving load and providing reserves to the system, subject to a number of physical and reliability constraints.All three mathematical formulationsshare a number of common elements.

Therefore, we first present the formulation used to model the ORDC policy in its entirety, and then highlight the key differences in the FRSP and Capacity Payment formulations. These formulationsare adapted from previous work (Levin and Botterud, 2015).

\subsubsection{ORDC}

\subsubsection{Objective Function}

The model seeks to minimize the total net cost of operation of the course of a one year period, while accounting for fixed investment and operating costs, variable operation and generation costs, the penalty costs associated with lost load or reserves scarcity events. In the ORDC formulation, the societal 
benefit generated through the provision reserves is a negative term in the objective function to represent a net benefit to the system. These benefits are defined by piecewise linear functions of the spinning-up reserves level and total reserves levels, and are based on the value of lost load (VOLL) and the marginal reduction in loss of load probability (LOLP) as additional reserves are provided. A more detailed explanation of how these curves are calculated follows later in this appendix.

$$
\begin{aligned}
\min \sum_{i \in I} \mathrm{u}_{i} \cdot\left(C_{i}\right. & \left.+F_{i}\right) \cdot \overline{P_{i}}+\sum_{i \in I} \sum_{t \in T} M C_{i} \cdot g_{i, t}+S U C_{i} \cdot y_{i, t}+S D C_{i} \cdot x_{i, t}+N L C_{i} \cdot z_{i, t} \cdot \overline{P_{i}} \\
& +\sum_{t \in T} V O L L \cdot e s_{t}-P T C \cdot w g_{t}-\sum_{t \in T} R B S_{t}\left[R s_{t}\right]+R B N S_{t}\left[R n s_{t}\right]
\end{aligned}
$$

Where,

$$
\begin{gathered}
R s_{t}=\sum_{i \in I} r s_{i, t}+w r_{i, t} \\
R n s_{t}=\sum_{i \in I} r s_{i, t}+w r_{i, t}+r n s_{i, t}
\end{gathered}
$$

Note that in our formulation the variable $r n s_{i, t}$ refers specifically to capacity at non-committed units that is available to provide generation within 30 minutes of receiving an instruction to do so (nonspinning reserves), while $r_{s}$ refers specifically to excess capacity at committed units that is immediately available to provide generation (spinning reserves). In the ERCOT system, the quantity of available spinning-up reserves is also included when determining the non-spinning reserves price-adder for the system, therefore it isincluded in $R n s_{i, t}$, and accordingly, inthe final term of equation (A1).

The total system cost is minimized subject to a number of constraints, as follows. 


\subsubsection{Load Balance}

A load balance constraint ensures that there is sufficient generation to meet demand in each time period. If load is left unserved a penalty cost is assessed.

$$
\sum_{i \in I} g_{i, t}+w g_{t}+e s_{t}=D_{t}(A 4)
$$

\subsubsection{Thermal Output}

Maximum and minimum generation constraints are applied to each unit type. Due to the integer nature of our formulation, it is not possible to track the generation levels of each individual unit. Therefore our approach implicitly assumes that all units of a given type are providing the same level of generation and reserves capacity. This is reasonable due to the fact that the units are identical. Moreover, comparisons of binary and integer formulations showed similar results for each. The maximum output level of each thermal unit is de-rated to account for forced outages, however we do not consider planned outages.

$$
\begin{gathered}
g_{i, t}+r s_{i, t} \leq z_{i, t} \cdot \overline{O_{i}} \quad \forall i \in I, t \in T(A 5) \\
g_{i, t} \geq z_{i, t} \cdot \underline{O_{i}} \quad \forall i \in I, t \in T(A 6)
\end{gathered}
$$

\subsubsection{Ramping}

Two ramping constraints are imposed to limit the ability of each generation type to change its output between periods in accordance with their hourly ramp rates.Because integer variables are used to group similar units, it is not possible to track the output levels of each individual unit. As a result, this formulation results in slightly greater potential generation flexibility than would be available if each unit were individually tracked. However, this effect mostly applies to units that are frequently committed and de-committed, which in practice are the NGCC and NGCT units. As these units are already assumed to have substantial flexibility, this additional relaxation does not have a significant impact on the overall results. 


$$
g_{i, t} \leq g_{i, t-1}+z_{i, t} \cdot R U_{i} \quad \forall i \in I, t \in T \neq 1(A 7)
$$$$
g_{i, t} \geq g_{i, t-1}-z_{i, t-1} \cdot R D_{i} \quad \forall i \in I, t \in T \neq 1(A 8)
$$

\subsubsection{Reserves}

Each committed unit can provide spinning-up reserves with any capacity that is not being used to generate electricity. These reserves must be available and able to provide generation output within ten minutes of receiving an instruction to do so. Therefore, the potential spinning-up reserve capacity of each unit type is constrained by its instantaneous ten minute ramp rate $\left(S P R_{i}\right.$ as a fraction of total unit capacity). Similarly, units that aren't committed can provide non-spinning reserves capacity, constrained by their ability to commit and ramp-up generation within 30 minutes of receiving an instruction to do so $\left(N S R_{i}\right)$

$$
\begin{gathered}
r s_{i, t} \leq z_{i} \cdot \overline{P_{i}} \cdot S P R_{i} \quad \forall i \in I, s \in S, t \in T \\
r n s_{i, t} \leq\left(u_{i}-z_{i}\right) \cdot \overline{P_{i}} \cdot N S R_{i}
\end{gathered}
$$

\subsubsection{Wind Balance}

The combination of wind generation, wind reserves and wind curtailment must be equal to the available wind resource in each period. The wind reserves variable $\left(w r_{i, t}\right)$ represents wind capacity that is curtailed in order to provide spinning-up reserves, while the wind curtailment variable $\left(w c_{i, t}\right)$ specifically represents wind capacity that is curtailed and not used to provided reserves. In practice $w c_{i, t}$ will generally only be greater than zero when wind capacity is not permitted to provide reserves, as in the case presented in section 4.2.1.1.

$$
w g_{t}+w r_{t}+w c_{t}=W_{t} \quad \forall t \in T
$$




\subsubsection{Unit Commitment}

The following constraints ensure that the number of units of each type that are committed are logically consistent and do not exceed the expansion variables.

$$
\begin{aligned}
& z_{i, t}=z_{i, t-1}+y_{i, t}-x_{i, t} \quad \forall i \in I, t \in T \neq 1 \\
& z_{i, t} \leq u_{i} \quad \forall i \in I, t \in T \\
& x_{i, t}, \quad y_{i, t}, \quad z_{i, t} \geq 0 \quad \forall i \in I, t \in T
\end{aligned}
$$

\subsubsection{Energy and Reserves Prices}

The energy price in each period is set equal to the dual variable of the load balance constraint (A4), while the spinning-up and non-spinning are set equal to the dual variable of the two reserve balance constraints, (A2) and (A3) respectively.

\subsubsection{Fixed Reserve Scarcity Price}

\subsubsection{Objective Function}

The objective function in the FRSP formulation is largely analogous to that in the ORDC formulation. The primary difference is that reserves provision is supported through a soft constraint, and therefore the benefits of reserves are not included in the objective function. Instead the scarcity penalties that are incurred when the soft constraints are violated appear as additional potential system costs.

$$
\begin{gathered}
\min \sum_{i \in I} \mathrm{u}_{i} \cdot\left(C_{i}+F_{i}\right) \cdot \overline{P_{i}}+\sum_{i \in I} \sum_{t \in T} M C_{i} \cdot g_{i, t}+S U C_{i} \cdot y_{i, t}+S D C_{i} \cdot x_{i, t}+N L C_{i} \cdot z_{i, t} \cdot \overline{P_{i}} \\
+\sum_{t \in T} E S C \cdot e s_{t}+S R S C \cdot r S s_{t}+N R S C \cdot \text { rnss }_{t}(A 15)
\end{gathered}
$$




\subsubsection{Operating Constraints}

The constraints detailed in equations (A4) through (A14) of the ORDC formulation also apply to the FRSP formulation. These ensure that load is balanced and that the physical constraints of the thermal generators are observed.

\subsubsection{Reserves}

Reserves constraints are applied for both spinning-up reserves and total (spinning plus non-spinning) reserves. It is assumed that curtailed wind capacity is able to provide spinning-up reserves $\left(w r_{t}\right)$ and it is also possible for a reserves shortfall to occur in which case a penalty cost is assessed as outlined in the objective function.

$$
\begin{gathered}
\sum_{i \in I} r s_{i, t}+w r_{t}+r s s_{t}=R R s_{t} \quad \forall t \in T(A 16) \\
\sum_{i \in I}\left(r s_{i, t}+r n s_{i, t}\right)+w r_{t}+r n s s_{t}=R R s_{t}+R R n s_{t} \quad \forall t \in T(A 17)
\end{gathered}
$$

Similar to the ORDC formulation described above and the convention of the ERCOT system, the nonspinning reserve constraint actually includes contributions from both spinning-up and non-spinning reserves, i.e. (A17) represents the total need for operating reserves in the system. Therefore, a system with all its units committed is still capable of meeting its non-spinning reserve requirement, provided that sufficient committed capacity is not actively generating. Note that for the ORDC formulation, in equation (1), the non-spinning reserve benefit term is also a function of the sum of spinning-up and nonspinning reserves in the system. 


\subsubsection{Energy and Reserves Prices}

The energy price in each period is set equal to the dual variable of the load balance constraint (A2), and the spinning-up and non-spinning reserves prices are set equal dual variables of their respective constraints (A16) and (A17).

\subsubsection{Capacity Payment}

\subsubsection{Objective Function}

The objective function in the CP formulation is almost identical to the one used in the FRSP formulation. The only difference is the inclusion of a fixed capacity payment for each unit type that reduces the effective cost of new generation units and therefore incentivizes additional capacity expansion.

$$
\begin{aligned}
\min \sum_{i \in I} \mathrm{u}_{i} \cdot\left(C_{i}\right. & \left.+F_{i}-C P\right) \cdot \overline{P_{i}}+\sum_{i \in I} \sum_{t \in T} M C_{i} \cdot g_{i, t}+S U C_{i} \cdot y_{i, t}+S D C_{i} \cdot x_{i, t}+N L C_{i} \cdot z_{i, t} \cdot \overline{P_{i}} \\
& +\sum_{t \in T} E S C \cdot e s_{t}+S R S C \cdot \operatorname{srs}_{t}+N R S C \cdot n r s_{t}(A 18)
\end{aligned}
$$

\subsubsection{Operating and Reserve Constraints}

The constraints detailed in equations (A4) through (A14) of the ORDC formulation also apply to the CP formulation. These ensure that load is balanced and that the physical constraints of the thermal generators are observed. The soft reserve constraints from the FRSP formulation (A16) and (A17) also apply to the capacity payment formulation.

\subsubsection{Energy and Reserves Prices}

There is a key difference between how energy and reserves prices are calculated under the capacity payment formulation, as described in section 2.1.5. The energy and reserve prices in each period are determined from the shadow prices of the constraints (A16) and (A17), as under the FRSP formulation. However, in periods when a reserve scarcity event occurs, the reserve penalty cost is subtracted out of 
the shadow prices to determine the resultant wholesale prices. In the event of load curtailment, the energy price is set to the VOLL. When a reserve scarcity event occurs, the energy price is typically equal to the marginal cost of generation plus the scarcity price. Therefore, when the scarcity price is removed, the remaining energy price is simply the marginal cost of generation. Similarly, the reserves prices tend towards zero when reserve scarcity pricing effects are removed.

As scarcity pricing effects are not included in wholesale electricity prices, generators are largely dependent on the capacity payments for the recovery of their fixed investment and operational costs. This is particularly true for those units with higher marginal costs of generation.

\subsection{Calculation of Operating Reserves Demand Curves}

On June $1^{\text {st }}, 2014$ the Electric Reliability Council of Texas (ERCOT) implemented a new procedure for pricing and valuing operating reserves in their system. Continuous demand curves were introduced for two different reserves products, On-Line (analogous with spinning-up in our analysis) and Off-Line (analogous with non-spinning) reserves. These cost curves were generated based on historical data from 2011 and 2012, that were used to estimate loss-of-load probability (LOLP)distributions as a function of the reserves level. These LOLP distributions were combined with an assumed value of lost load (VOLL) to develop cost curves that represent the marginal value of an additional unit of reserves at any given reserves level. Separate curves were created for each of four seasonal bins and six daily bins, resulting in 24 total curves for each product. These curves are to be updated regularly as new data are made available. The ORDCs are used in real-time operations to generate "price-adders" that represent the marginal system cost of each reserves product and are added to the system energy price for that period. The methodology for calculating these prices-adders is reviewed briefly below, for more a more detailed account see ERCOT (2013). 
The non-spinning (Off-Line) reserves price-adder in a given period is calculated in accordance with equation 19).

$$
P_{n s}=0.5 \cdot(V O L L-\lambda) \cdot\left(1-C D F\left(\mu_{h, m, w}, \sigma_{h, m, w}, r s+r n s-X\right)\right)
$$

Where $\lambda$ is the shadow price of power balance constraint ${ }^{5}$ and CDF is the cumulative density function of the normal distribution with mean $\mu_{h, m, w}$ and standard deviation $\sigma_{h, m, w}$, which are derived from the LOLP distributions that are based on historical data. $X$ is the minimum reserves contingency level for the system (2000 MW), and VOLL is the value of lost load ( $\$ 9000 / \mathrm{MWh})$. The indices $h, m$ and $w$, represent the operating hour, month and system wind penetration level as a percentage of total annual loadrespectively ${ }^{6}$. Similarly, the spinning-up reserves price is calculated as follows ${ }^{7}$.

$$
P_{s}=P_{n s}+0.5 \cdot \max (\operatorname{VOLL}-\lambda, 0) \cdot\left(1-\operatorname{CDF}\left(\frac{\mu_{h, m, w}}{2}, \frac{\sigma_{h, m, w}}{\sqrt{2}}, r s-X\right)\right)
$$

In each period, a market clearing price is determined for each reserves product according to the value of the ORDC curve that corresponds with the provided reserves level. The market clearing price of each product is therefore equal to the value of its marginal contribution to system reliability.

\footnotetext{
${ }^{5}$ As our model co-optimizes generation and reserves, the shadow price of the power balance constraint is not available as an input into the ORDC calculation. Therefore, for the purposes of calculating the ORDC, we assume that $\lambda$ is equal to the marginal cost of generation from a NGCC unit.

${ }^{6}$ ERCOT's published methodology does not explicitly discuss how the ORDCs might shift as wind penetration increases. Rather, appropriate values for $\mu$ and $\sigma$ are determined given current system conditions and will be updated over time as wind levels increase. We introduce the index $w$ and accompanying methodologyfor adjusting these values, as detailed in equations (21) and (22), specifically for our analysis.

${ }^{7}$ For efficient integration with our MIP formulation, it is necessary to ensure that $P_{n s}$ is a function of the non-spinning reserves level alone. Therefore, for the purposes of deriving the reserves curves, we assume that $25 \%$ of total reserves are non-spinning and $75 \%$ are spinning. This is roughly in-line with historical data in ERCOT and has a minimal impact on the final result. This assumption is used only for the calculation of the non-spinning reserves price (which is generally close to 0 ), and in no way constrains the actual distribution of operational reserves that are determined by the model.
} 
ERCOT system operators will adjust these ORDCs periodically to reflect changes in in system conditions.

As we are interested in understanding a range of potential impacts related to increased wind

penetration, we develop our own methodology to account for the increased net load uncertainty and

variability that occurs in the presence of increased wind generation as follows. Using ERCOT 2013 hourly

wind generation data, we estimate and isolate the components of the mean and standard deviation of

LOLP distribution that are due to wind variability. These components are then scaled with increasing

wind penetration $(w)$, assuming a current penetration of $10 \%$ in ERCOT. The mean component scales

linearly with wind penetration level ${ }^{8}$, while the standard deviation scales with the square root of wind

penetration level.

$$
\begin{gathered}
\mu_{h, m, w}=\mu_{h, m, 10} \cdot\left(\frac{w}{10}\right) \\
\sigma_{h, m, w}=\sigma_{h, m, 10} \cdot\left(\sqrt{\frac{w}{.10}}\right)
\end{gathered}
$$

\footnotetext{
${ }^{8}$ This linear scaling with assumes that geographic diversity and the corresponding aggregate wind forecasting error does not change with increasing wind penetration. This is a simplifying assumption that may mildly overestimate the variability introduced by additional wind generation if additional geographically diverse sites are introduced. However, it is a reasonable first order assumption that we feel is appropriate for our scope of analysis.
} 


\begin{tabular}{|c|c|c|c|}
\hline RTO/ISO & $\begin{array}{l}\text { Capacity } \\
\text { Market }\end{array}$ & $\begin{array}{l}\text { Reserve Scarcity } \\
\text { Pricing }\end{array}$ & Description \\
\hline CAISO & $\mathrm{No}^{1}$ & Fixed/Graduated & $\begin{array}{l}\text { Graduated scarcity prices for non-spinning reserves and } \\
\text { regulation-down, fixed scarcity price for regulation-up } \\
\text { and spinning reserves. }\end{array}$ \\
\hline ERCOT & No & ORDC & $\begin{array}{l}\text { ORDCs for spinning and non-spinning reserves with a } \\
2,000 \mathrm{MW} \text { minimum contingency level }\end{array}$ \\
\hline ISO-NE & Yes & Fixed & Fixed scarcity prices for multiple reserves products \\
\hline MISO & Yes & Fixed/Graduated & $\begin{array}{l}\text { Fixed scarcity prices for small events, two-step scarcity } \\
\text { pricing curve based on probability of lost load for larger } \\
\text { events }\end{array}$ \\
\hline NYISO & Yes & Fixed/Graduated & $\begin{array}{l}\text { Graduated scarcity prices for regulation and } 30 \text {-minute } \\
\text { operating reserves, fixed for ten-minute and spinning } \\
\text { reserves. Three different zones. }\end{array}$ \\
\hline PJM & Yes & Graduated & $\begin{array}{l}\text { Two-step scarcity pricing system for synchronous and } \\
\text { non-synchronous reserves }\end{array}$ \\
\hline SPP & No & Fixed & $\begin{array}{l}\text { Fixed scarcity prices for supplemental, spinning, } \\
\text { regulation-up and regulation-down reserves }\end{array}$ \\
\hline
\end{tabular}

\footnotetext{
${ }^{1}$ CAISO has a capacity planning procedure where utilities are required to maintain a specified planning reserve margin, but currently does not operate a centralized capacity market (Ela et al., 2014).
} 


\begin{tabular}{lrrrrr} 
Parameter & Nuclear & \multicolumn{1}{c}{ Coal } & NGCC & NGCT & Wind \\
\hline \hline Capacity (MW) & 2,200 & 1,300 & 400 & 210 & - \\
Max. Output (MW) & 2,046 & 1,214 & 378 & 202 & - \\
Min. Output (MW) & 2,046 & 520 & 160 & 84 & - \\
Overnight Cost (\$/kW) & 5,501 & 2,925 & 1,021 & 673 & 1,630 \\
Fixed OM (\$/kW) & 93.28 & 31.18 & 15.37 & 7.04 & 39.55 \\
Annualized Fixed and Investment Cost (\$/MW) & 373,595 & 297,416 & 78,186 & 51,537 & 164,317 \\
Var OM (\$/MWh) & 2.14 & 4.47 & 3.27 & 10.37 & - \\
Heat Rate (btu/kWh) & 10,464 & 8,740 & 6,333 & 10,450 & - \\
Fuel Cost (\$MMtu) & 0.50 & 2.34 & 4.96 & 9.60 & - \\
Marginal Generation Cost (\$/MWh) & 7.37 & 23.80 & 30.64 & 55.00 & - \\
No Load Cost (\$/MW) & - & 1.10 & 4.78 & 8.86 & - \\
Max Spinning Reserve (\% of Max. Output) & - & $20 \%$ & $50 \%$ & $80 \%$ & - \\
Ramp Up Limit (\% of Max. Output/hr) & - & $35 \%$ & $50 \%$ & $100 \%$ & - \\
Ramp Down Limit (\% of Max. Output/hr) & - & $35 \%$ & $50 \%$ & $100 \%$ & - \\
Start-Up Cost (\$/MW) & - & 131.35 & 61.80 & 40.60 & - \\
Shut-Down Cost (\$/MW) & - & 1.31 & 0.62 & 0.41 & - \\
Forced Outage Rate & $7.00 \%$ & $6.60 \%$ & $7.70 \%$ & $7.70 \%$ & -
\end{tabular}


Table 3

\begin{tabular}{lr} 
Parameter & \multicolumn{1}{c}{ Value } \\
\hline \hline Peak Load (MW) & 77,471 \\
Existing Generation Capacity (MW) & 73,380 \\
$\quad$ Nuclear & 4,400 \\
Coal & 19,500 \\
NGCC & 43,600 \\
NGCT & 5,880 \\
Wind Capacity Factor & $33.0 \%$
\end{tabular}



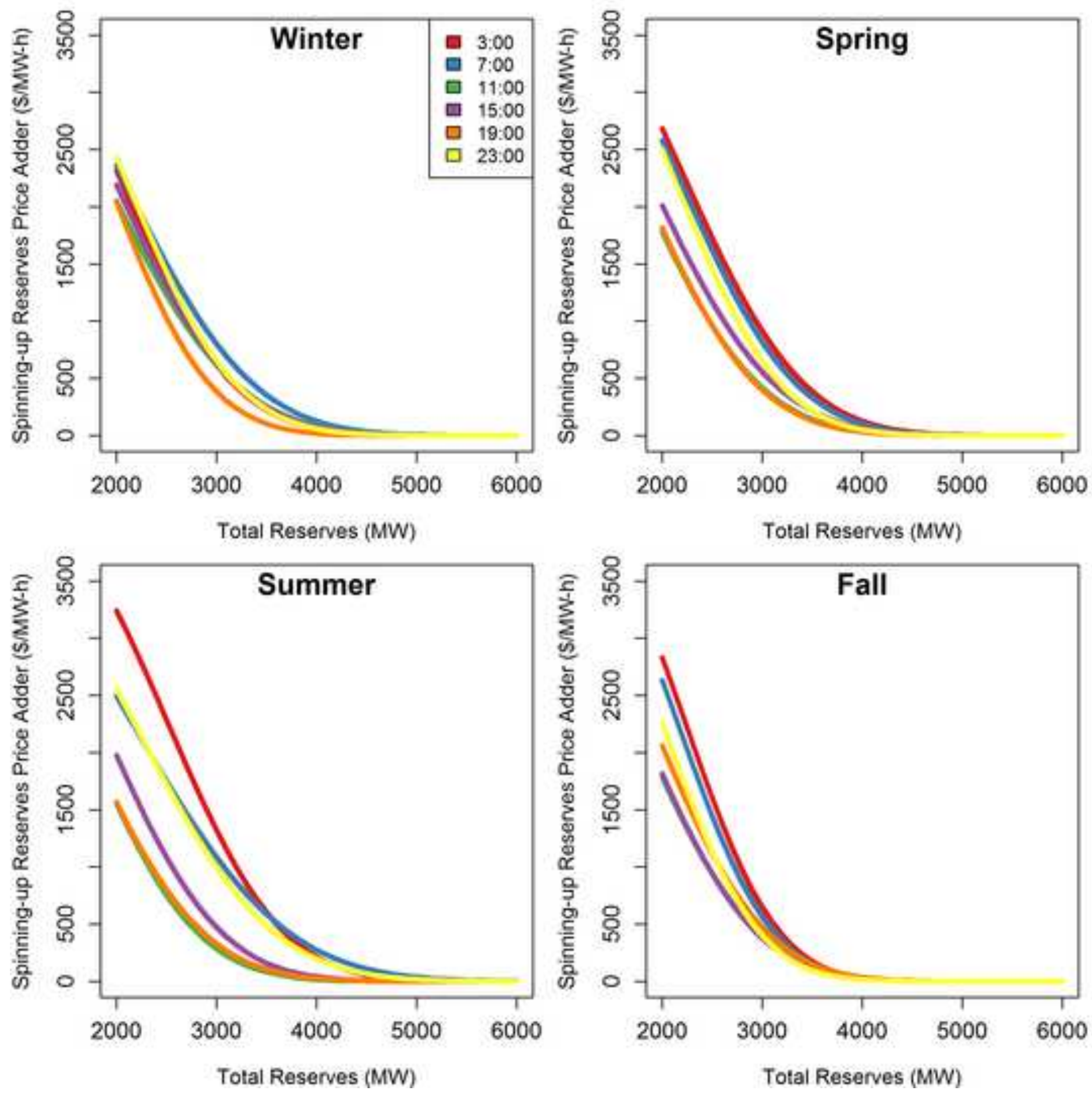
Figure 2

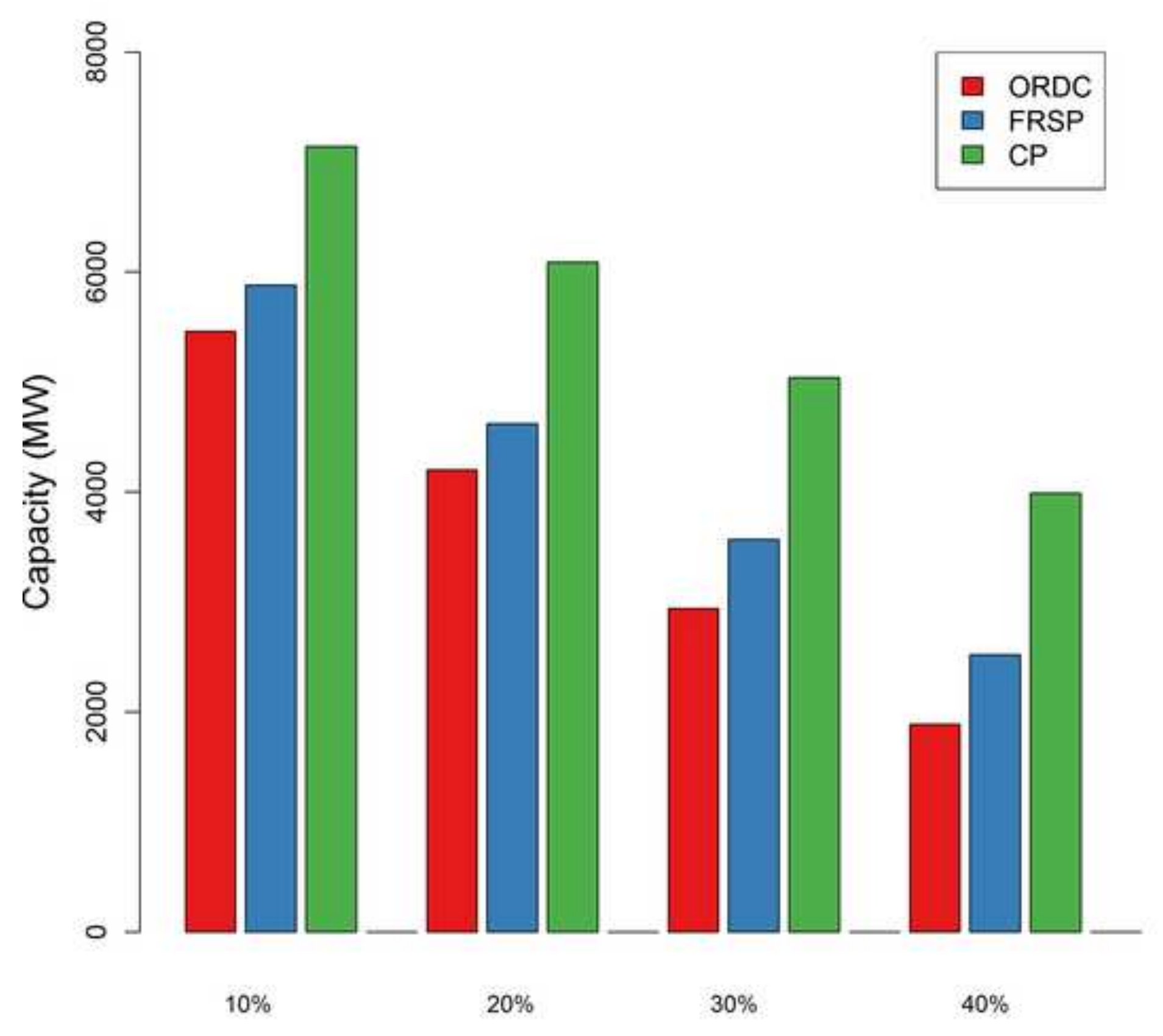




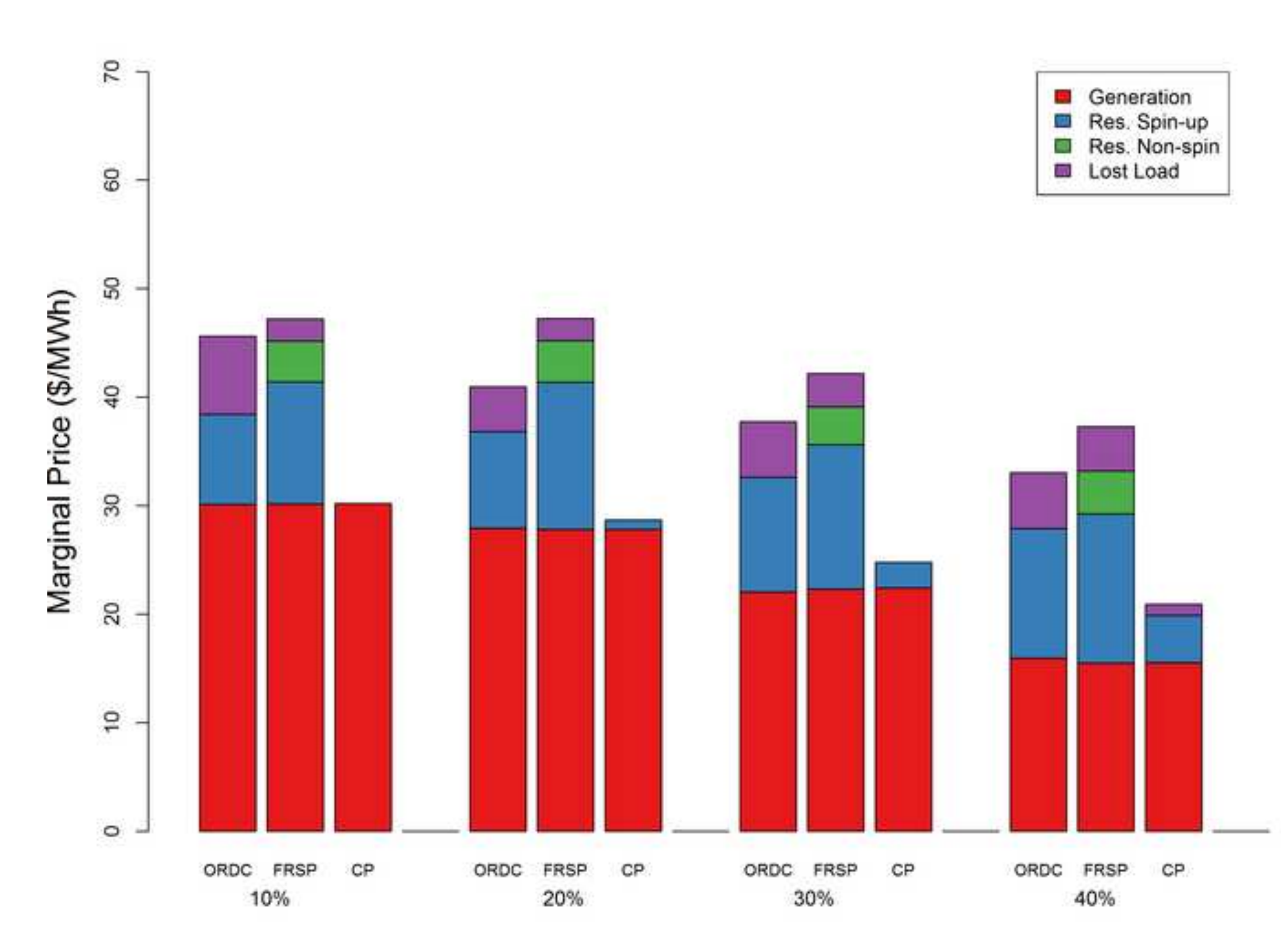




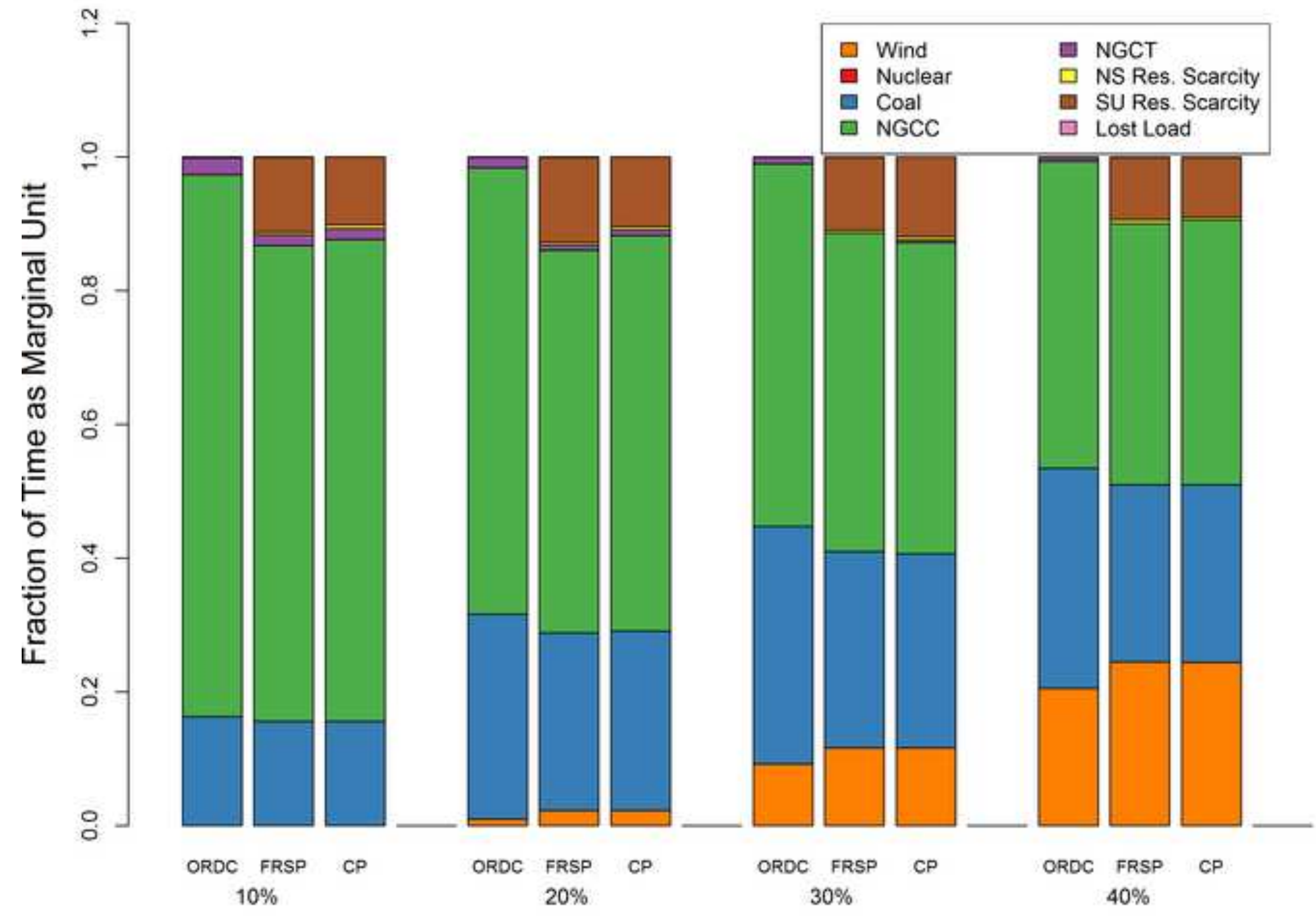


Figure 5

5

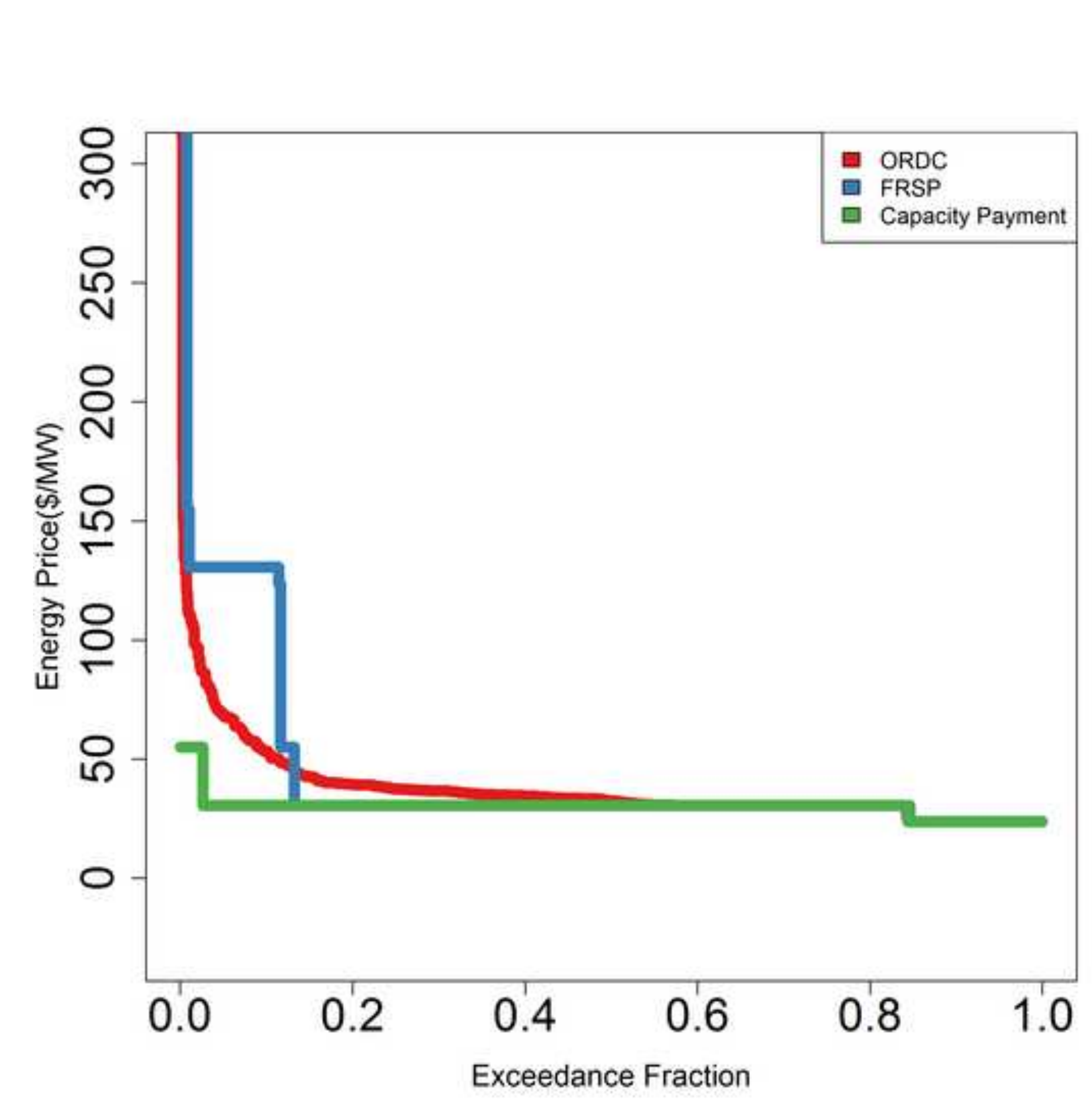

.

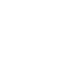

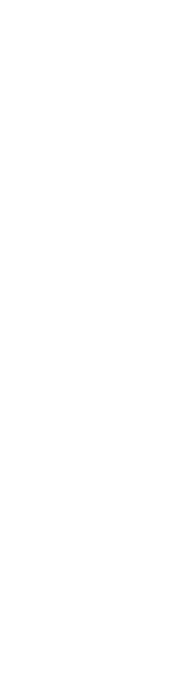




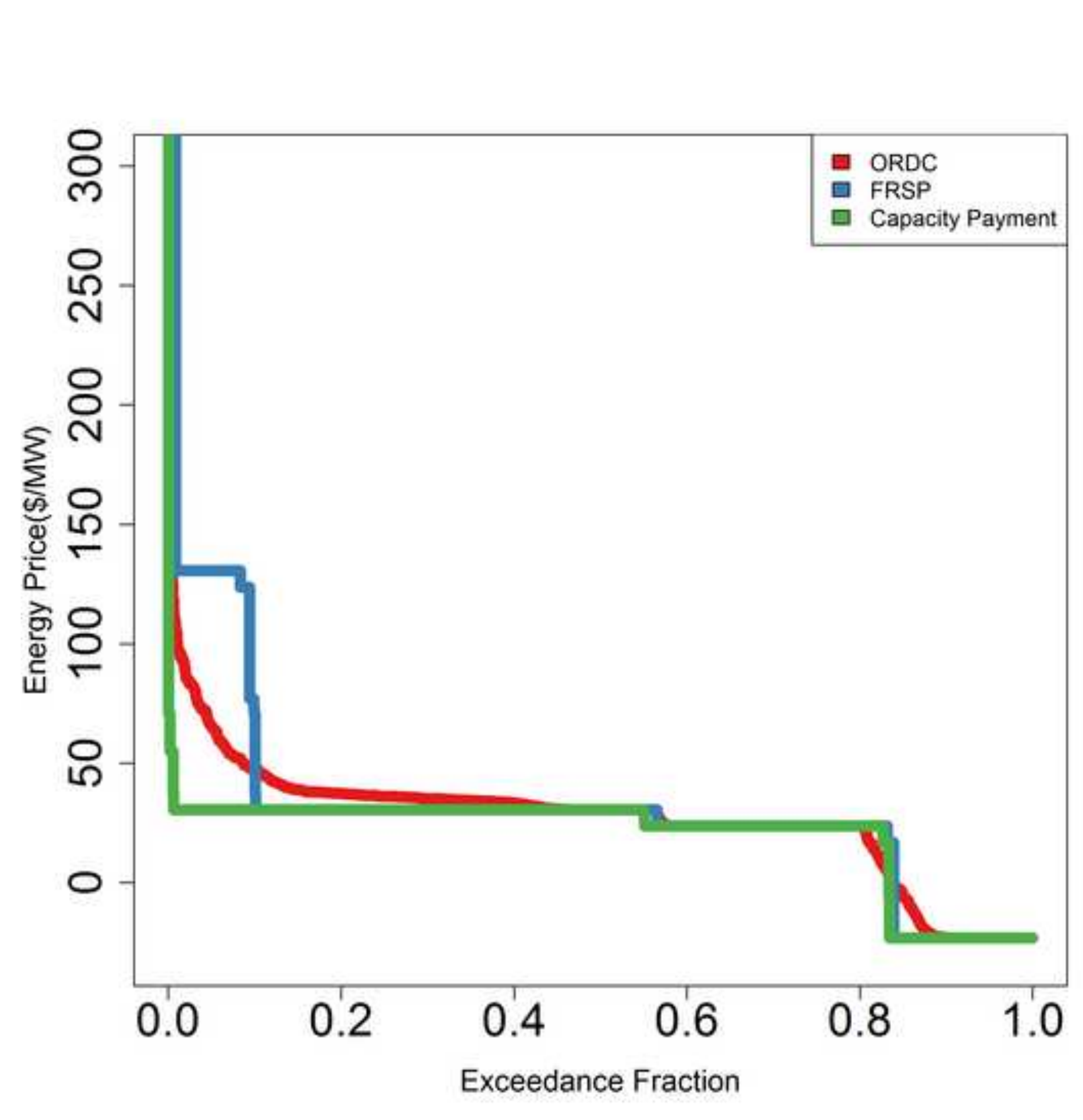

Figure 6

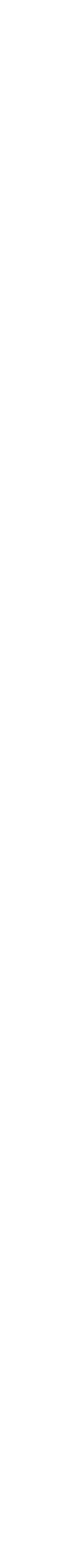




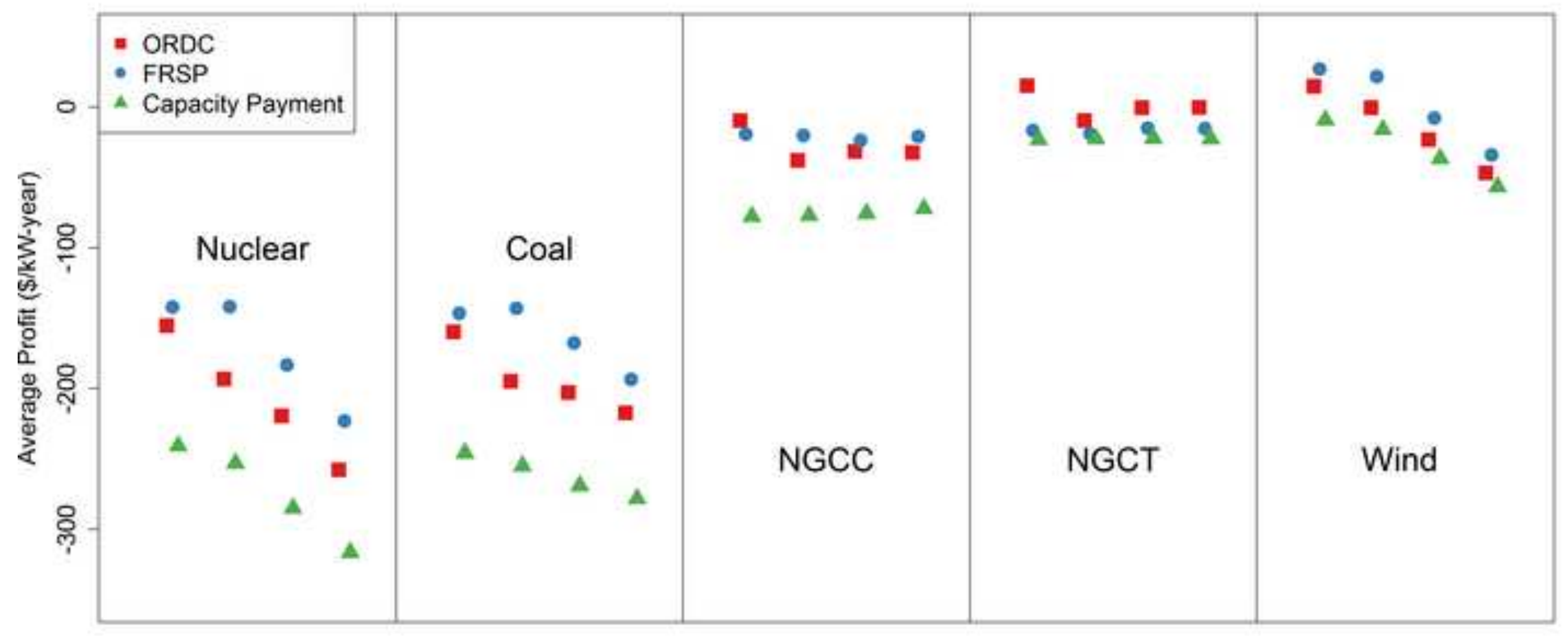

$10 \% 20 \% 30 \% \quad 40 \%$

$10 \% \quad 20 \% \quad 30 \% \quad 40 \%$

$10 \% \quad 20 \% \quad 30 \% \quad 40 \%$

$10 \% \quad 20 \% 30 \% \quad 40 \%$

$10 \% \quad 20 \% \quad 30 \% \quad 40 \%$ 


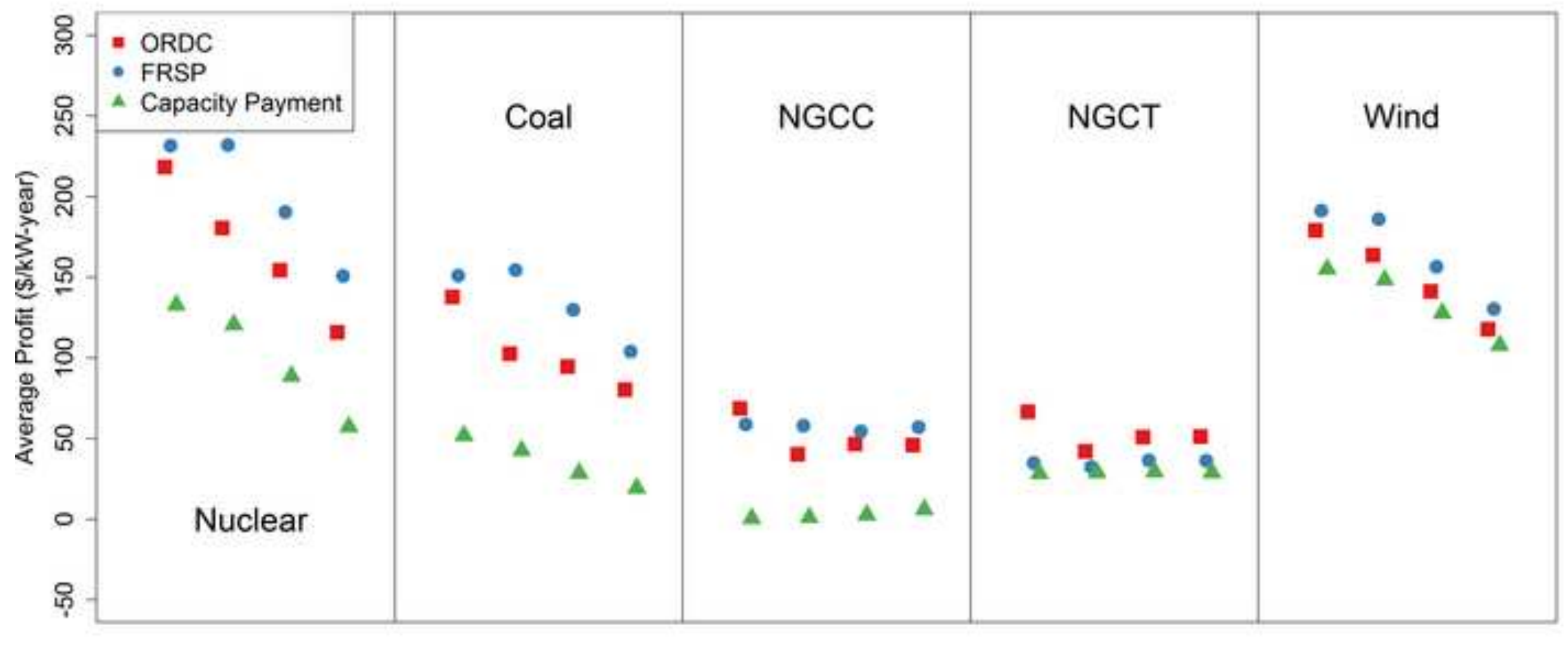

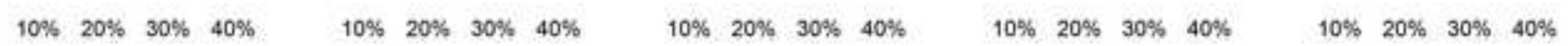




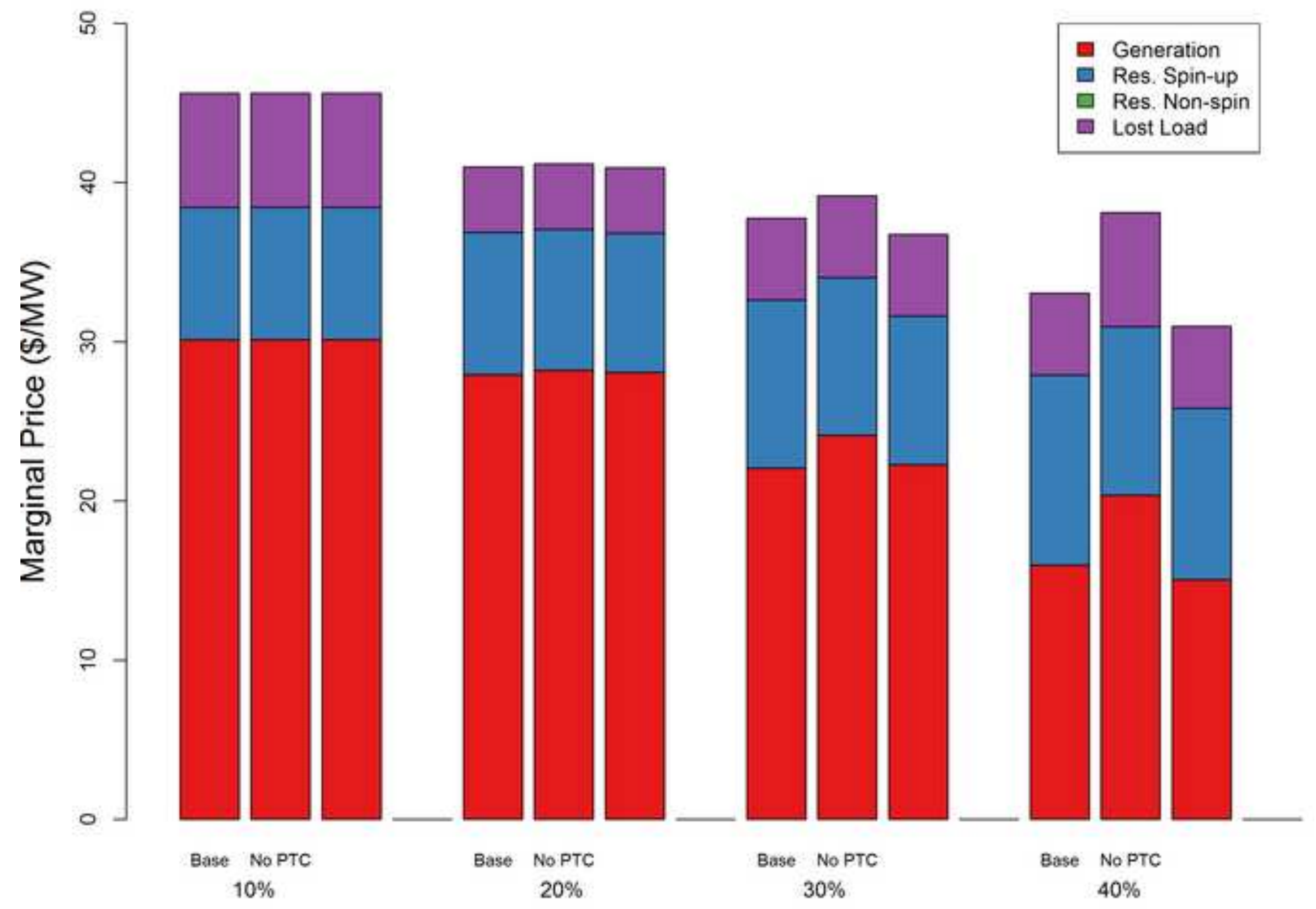




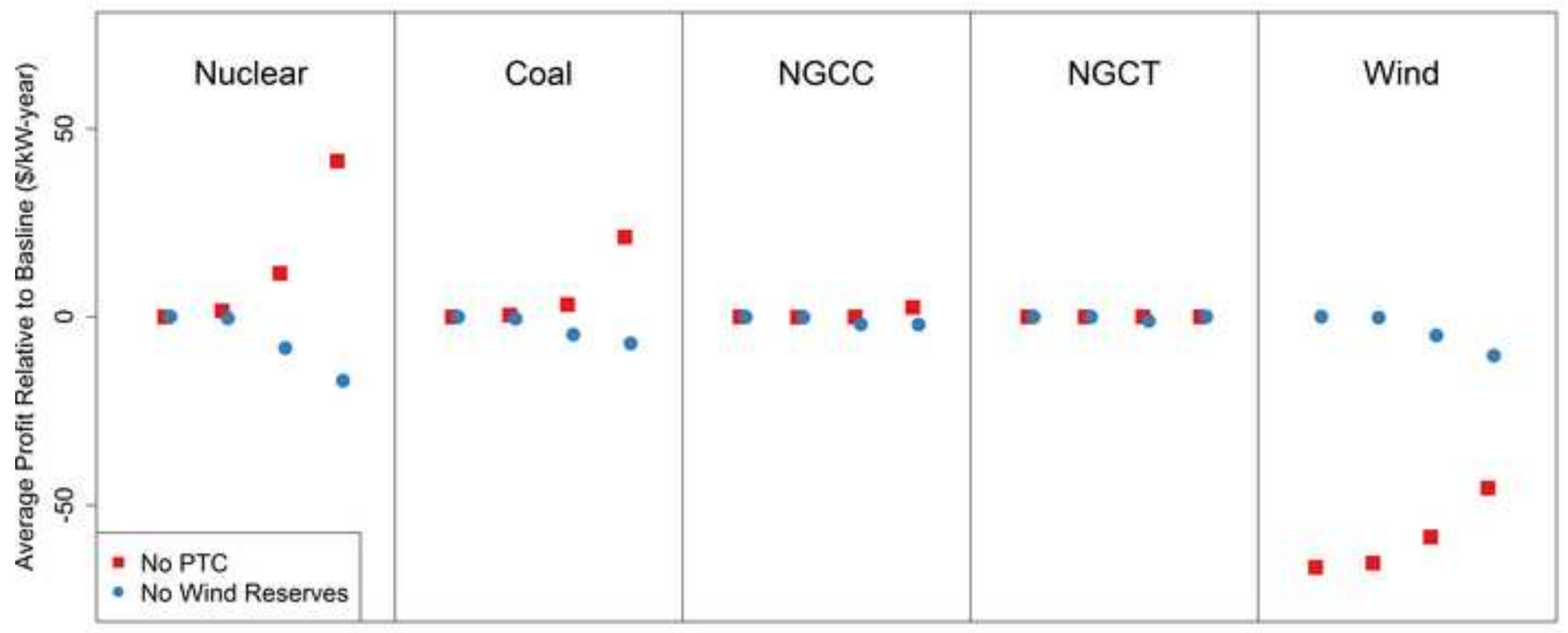

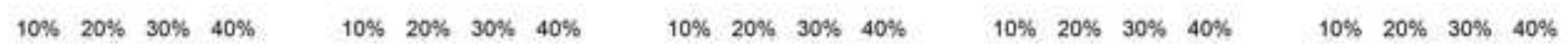




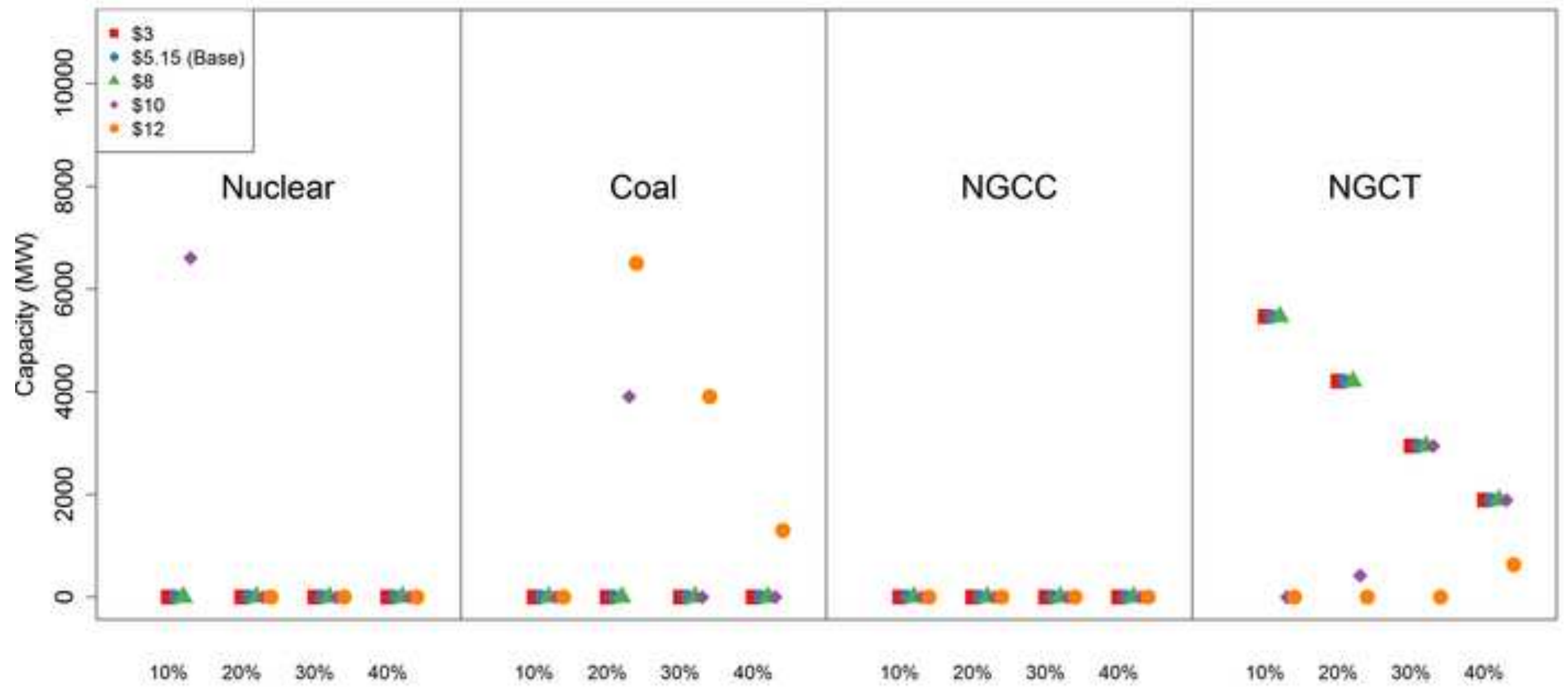




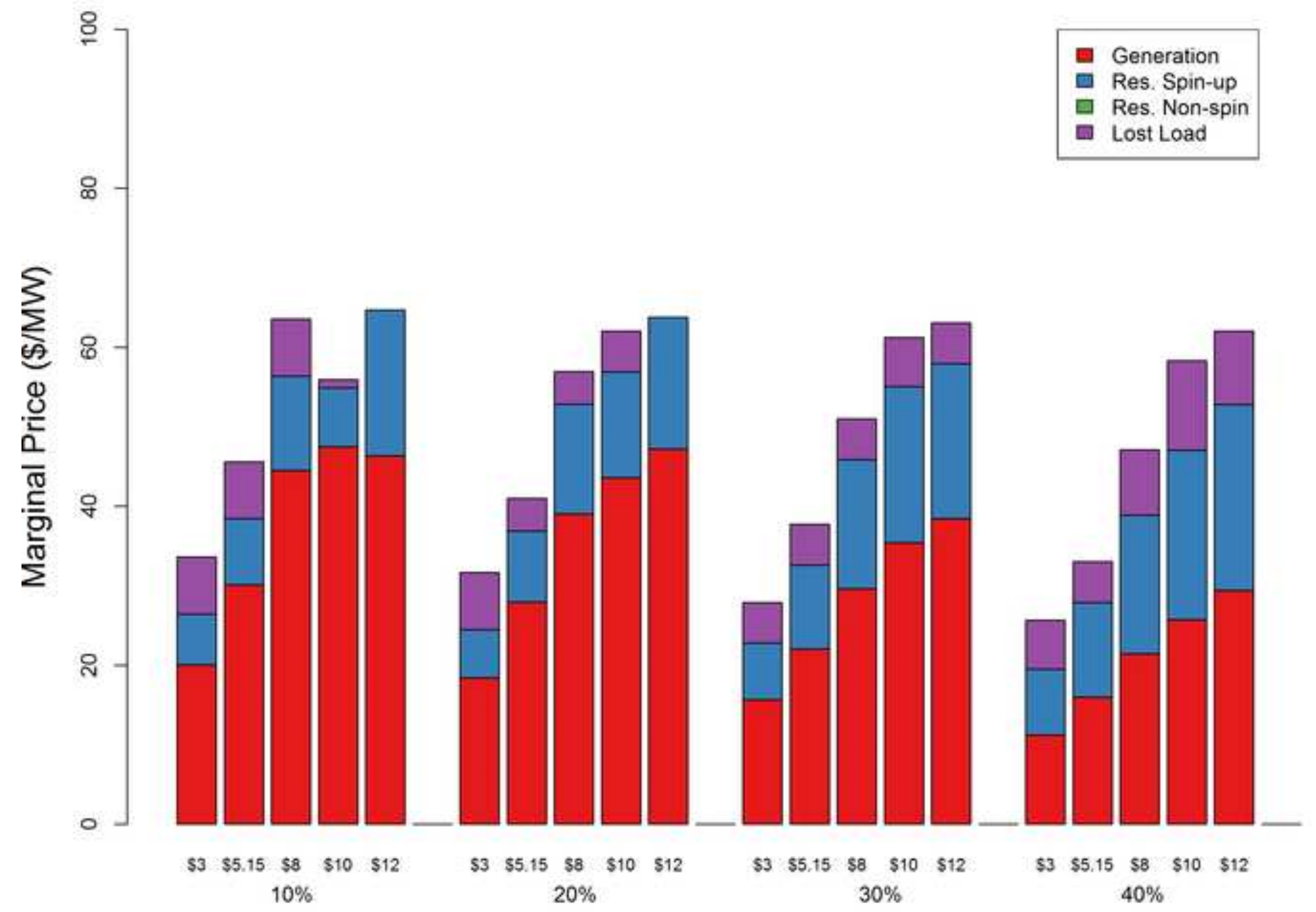




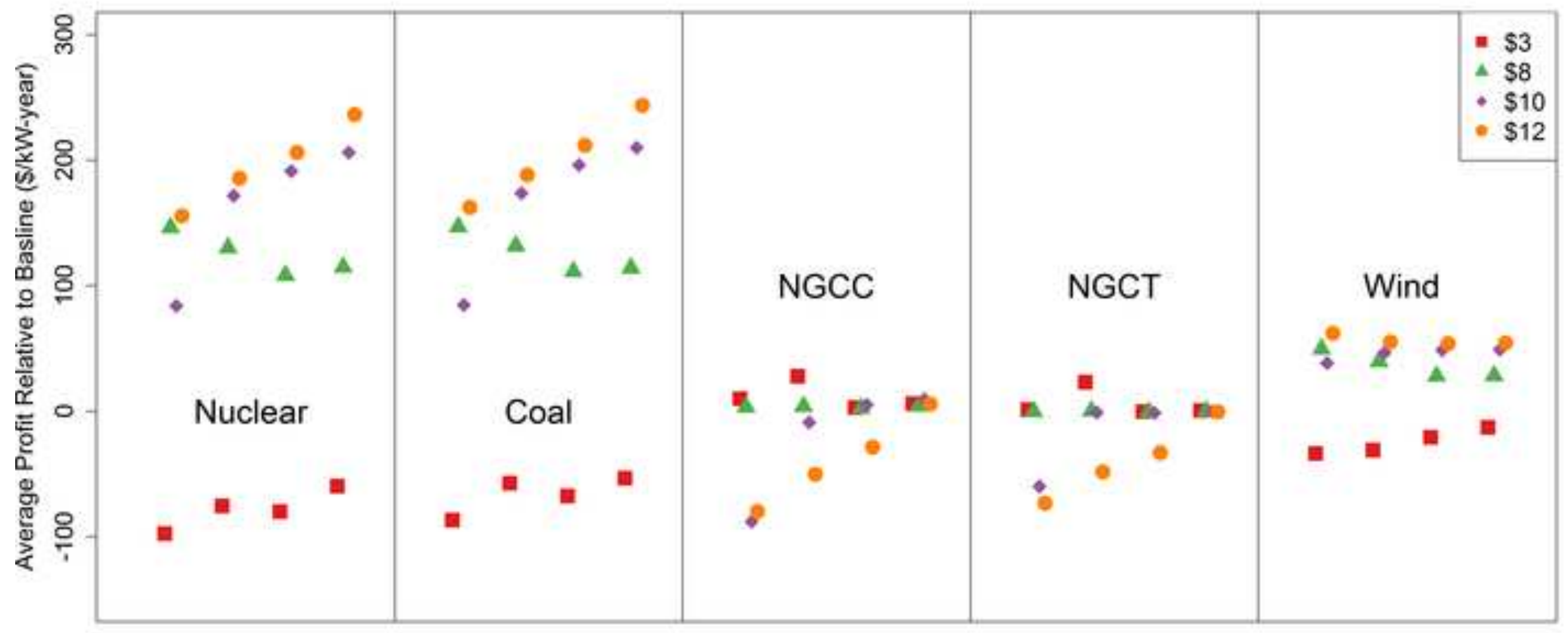

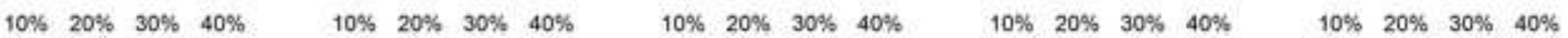

